\title{
Certain Type Turbofan Engine Whole Vibration Model with Support Looseness Fault and Casing Response Characteristics
}

\author{
H. F. Wang and G. Chen \\ College of Civil Aviation, Nanjing University of Aeronautics and Astronautics, Nanjing 210016, China \\ Correspondence should be addressed to H. F. Wang; wanghaifei1986318@163.com
}

Received 13 July 2014; Revised 30 September 2014; Accepted 30 September 2014; Published 17 December 2014

Academic Editor: Tony Murmu

Copyright ( 2014 H. F. Wang and G. Chen. This is an open access article distributed under the Creative Commons Attribution License, which permits unrestricted use, distribution, and reproduction in any medium, provided the original work is properly cited.

\begin{abstract}
Support looseness fault is a type of common fault in aeroengine. Serious looseness fault would emerge under larger unbalanced force, which would cause excessive vibration and even lead to rubbing fault, so it is important to analyze and recognize looseness fault effectively. In this paper, based on certain type turbofan engine structural features, a rotor-support-casing whole model for certain type turbofan aeroengine is established. The rotor and casing systems are modeled by means of the finite element beam method; the support systems are modeled by lumped-mass model; the support looseness fault model is also introduced. The coupled system response is obtained by numerical integral method. In this paper, based on the casing acceleration signals, the impact characteristics of symmetrical stiffness and asymmetric stiffness models are analyzed, finding that the looseness fault would lead to the longitudinal asymmetrical characteristics of acceleration time domain wave and the multiple frequency characteristics, which is consistent with the real trial running vibration signals. Asymmetric stiffness looseness model is verified to be fit for aeroengine looseness fault model.
\end{abstract}

\section{Introduction}

Looseness fault is a common fault in rotating machinery, which is caused by low installation quality or long-term vibration. When looseness fault exists in rotor-support-casing system, rotor will be lifted up periodically; if the unbalanced force in rotor system is greater than the gravitational force, it will cause severe vibration. Serious looseness fault may lead to rub-impact fault between the rotor and the stator. Therefore, effective identification of the looseness fault is of great significance.

At present, many scholars have carried out a few works on the looseness fault, mostly based on a lumped-mass model. Muszynska and Goldman [1] studied one-lateralmode unbalanced and radical side-loaded rotor with either a loose pedestal or occasional rotor-to-stator rubbing, which exhibited regular periodic vibrations of synchronous $(1 \times)$ and subsynchronous $(1 / 2 \times, 1 / 3 \times, \ldots)$ orders, as well as chaotic vibration patterns of the rotor, all accompanied by higher harmonics. Goldman and Muszynska [2] developed an analytical algorithm for investigating local nonlinear effects in rotor systems. They used a specially developed variable transformation that smoothes discontinuities, and then they applied an averaging technique. Their results showed good agreement with experimentally observed typical behaviors and orbits of rubbing rotors. In the last two papers, the effects of pedestal looseness on the system response were also studied. Muszynska [3] studied a mathematical model of this phenomenon for loose rotating parts in rotating machines. Chu and Tang [4] established a nonlinear mathematical model, containing stiffness and considering damping forces with trilinear forms. The shooting method was used to obtain the periodic solutions of the system. Stability of these periodic solutions was analyzed by using the Floquet theory. Perioddoubling bifurcation and Neimark-Sacker bifurcation were found. Finally, the governing equations were integrated by the fourth-order Runge-Kutta method. Three kinds of routes to or out of chaos, that is, period-to-chaos, quasiperiodic route, and intermittence, were found. Chen [5] established a new rotor-ball bearing-stator coupling dynamics model and the nonlinear dynamic response characteristics of rotorball bearing-stator system under unbalance and looseness 
coupling faults were obtained. $\mathrm{Lu}$ and $\mathrm{Chu}$ [6] studied the looseness fault of rotor system by experiments. The characteristics of multiple frequency and frequency division were found. Ji and $\mathrm{Zu} \mathrm{[7]} \mathrm{analyzed} \mathrm{the} \mathrm{free} \mathrm{and} \mathrm{forced} \mathrm{vibration}$ of a nonlinear bearing system to illustrate the nonlinear effect on the free and forced vibrations of the system by the method of multiple scales. He et al. [8] and Lee and Choi [9] studied fault diagnosis of rotor systems with pedestal looseness with different analytical methods, such as genetic algorithm and Hilbert-Huang transform. Reddy and Sekhar [10] used artificial neural networks to identify unbalance and looseness. Ma et al. [11] set up a mechanical model of looseness of fastening bolt on the bearing pedestal and investigated the dynamic characteristics of rotor by using the nonlinear oil-film model.

In recent years, the finite element method has been used to establish looseness fault model by domestic and foreign scholars. Behzad and Asayeshthe [12] proposed a finite element method for studying the effects of loose rotating disks on the rotor-bearing systems' response. Lee et al. [13] studied a generalized finite element modeling method of a rotor-bearing system by using the state-space Newmark method based on the average velocity concept. Ma et al. [14] established a finite element model of a rotor system with pedestal looseness stemming from a loosened bolt and the effects of the looseness parameters on its dynamic characteristics were analyzed.

However, at present, there are a few works on support looseness fault analysis in aeroengine. Due to the low bearing stiffness in aeroengine, the wide use of thin-walled structure in rotor and casing, its great flexibility, and the casing acceleration signal are important to distinguish aeroengine faults, so aimed at certain type turbofan engine, it is of great significance to establish a whole model of a rotor-bearingcasing coupling system and make research on the acceleration response characteristics of the looseness fault.

In this paper, a finite element model of certain type turbofan engine with looseness fault is established. The looseness fault between the bearing and the casing in the model is studied. Numerical integration method is used to solve the response of the system. The response characteristics of the casing acceleration from the time domain and frequency domain are analyzed. Finally, the simulation is compared with the real trial running vibration signals of the turbofan engine, and connector looseness characteristics are analyzed. It is proved that the aeroengine support looseness fault model is valid.

\section{A Dynamic Model for Certain Type Turbofan Engine}

2.1. The Structure Sketch Map for Certain Type Turbofan Engine. Rotor-bearing-casing structure sketch map for certain type turbofan engine is shown in Figure 1. The symbols in Figure 1 are described as follows: $P_{1}$ denotes fan disk; $P_{2}$ denotes motor disk; $P_{3}$ denotes compressor disk; $P_{4}$ denotes the first turbine disk; $P_{5}$ denotes the second turbine disk;
$C_{1}$ denotes the intermediate casing; $G_{1}$ denotes the gear coupling between the fan shaft and the transmission shaft; $G_{2}$ denotes the gear coupling between the transmission shaft and the compressor shaft; $G_{3}$ denotes the gear coupling between the compressor shaft and the turbine shaft; $S_{1}$ denotes the fan support point bearings; $S_{2}$ denotes the compressor front support bearings; $S_{3}$ denotes the compressor rear support bearings; $S_{4}$ denotes the turbine support bearings; $I_{1}$ denotes the front installation node; $I_{2}$ denotes the back installation node; $k_{g}$ is the mesh stiffness of a gear pump; $k_{f 1}, k_{f 2}, k_{f 3}$, and $k_{f 4}$ are the support stiffness between the rotor and the casing; and $k_{c}$ is the connection stiffness between the casing and the base.

The rotor-support-casing coupling dynamic model for a turbofan engine is established. Its concrete methods for modeling are described as follows.

\subsection{Dynamics Model}

2.2.1. Rotor Model. The rotor is composed of a number of rigid rotating disks and elastic shaft. The elastic shaft is discreted by beam element model, and the shear deformations and gyroscopic moments and inertias of shaft are considered; the rigid rotating disk is modeled as discrete lumped mass, and the mass, inertias, and gyroscopic moments are considered. All parts are coupled by nonlinear forces and moments. The finite element rotor dynamic model is shown in Figure 2.

The symbols in Figure 2 are described as follows: for each rotor shaft beam element, $E, I, G, \mu, L, \rho$, and $A$, respectively, are the elastic modulus, moment of inertia, shear modulus, Poisson's ratio, shaft length, shaft density, and shaft cross-sectional area. $P_{i}$ is the rigid rotating disks; $F_{x i}, F_{y i}$, $M_{x i}$, and $M_{y i}$ are forces and moments which act on the $i$ th node of rotor in the $X$ and $Y$ directions. $X Y Z$ in Figure 3 is a fixed coordinate system; under deformation state, any cross-section's position relative to the fixed coordinate system is determined as follows: elastic shaft centerline position is determined by the displacement $x$ in the $X$ direction and the displacement $y$ in the $Y$ direction; cross-section orientation $\phi$ is determined by the angle around the $x$-axis and the angle $\Psi$ around the $y$-axis; in addition, the cross-section also rotates around the $z$-axis.

(1) Motion Equations of Rigid Disk Element. Suppose the circular disk's mass is $m_{d}$, diameteral moment of inertia is $J_{d d}$, and polar moment of inertia is $J_{P d}$; polar moment of inertia $J_{P d}=2 J_{d d}$, andthe second term refers to "disk," shown as $P_{1}, P_{2}, \ldots, P_{M} ; \omega$ is the disk's rotating speed. Through the Lagrange equation we can obtain the motion equations of rigid disk relative to the fixed coordinate system:

$$
\left(\mathbf{M}_{T d}+\mathbf{M}_{R d}\right) \ddot{\mathbf{q}}_{d}-\omega \mathbf{G}_{d} \dot{\mathbf{q}}_{d}=\mathbf{Q}_{d}
$$

where $\mathbf{Q}_{d}$ is the generalized external force vector; $\mathbf{M}_{T d}$ and $\mathbf{M}_{R d}$ are, respectively, the mass matrix and the mass 


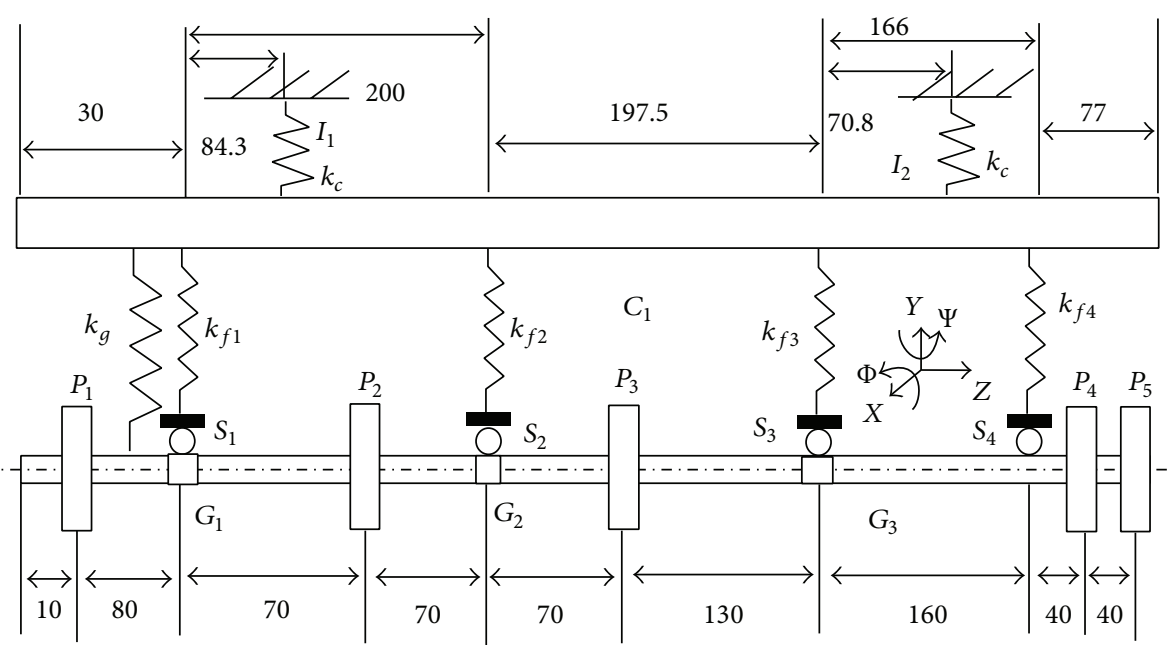

FIGURE 1: Rotor-bearing-casing model sketch map of a type of aeroengine (unit: mm).

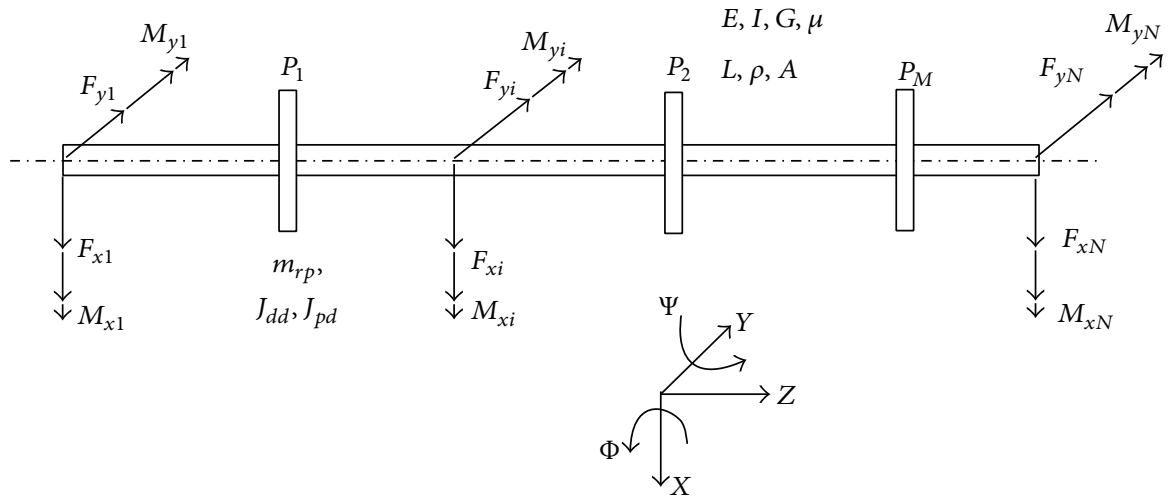

Figure 2: The finite element rotor dynamic model.

inertia matrix; $\mathbf{G}_{d}$ is gyroscopic matrix; and $\mathbf{q}$ is generalized displacement vector, $\mathbf{q}=[x, y, \phi, \psi]$. Then,

$$
\begin{aligned}
\mathbf{M}_{T d}=\left[\begin{array}{cccc}
m_{d} & 0 & 0 & 0 \\
0 & m_{d} & 0 & 0 \\
0 & 0 & 0 & 0 \\
0 & 0 & 0 & 0
\end{array}\right], \quad \mathbf{M}_{R d}=\left[\begin{array}{cccc}
0 & 0 & 0 & 0 \\
0 & 0 & 0 & 0 \\
0 & 0 & J_{d d} & 0 \\
0 & 0 & 0 & J_{d d}
\end{array}\right], \\
\mathbf{G}_{d}=\left[\begin{array}{cccc}
0 & 0 & 0 & 0 \\
0 & 0 & 0 & 0 \\
0 & 0 & 0 & -J_{p d} \\
0 & 0 & J_{p d} & 0
\end{array}\right] .
\end{aligned}
$$

(2) Motion Equations of Beam Element. In this paper, the beam element is adopted, and each beam element has 2 nodes and 8 DOFs, and each node has 4 DOFs, which are, respectively, the displacements $x$ and $y$ in the $X$ and $Y$ directions, and rotating angles $\phi$ and $\Psi$ around the $x$-axis and $y$-axis. The cross-section's displacement of the element is the function of the time and the position along the element axis. The generalized displacement vector of the element is $\mathbf{q}_{e}(t)=$ $\left[\begin{array}{llllllll}q_{1 e} & q_{2 e} & q_{3 e} & q_{4 e} & q_{5 e} & q_{6 e} & q_{7 e} & q_{8 e}\end{array}\right]^{T}$. Through the Lagrange

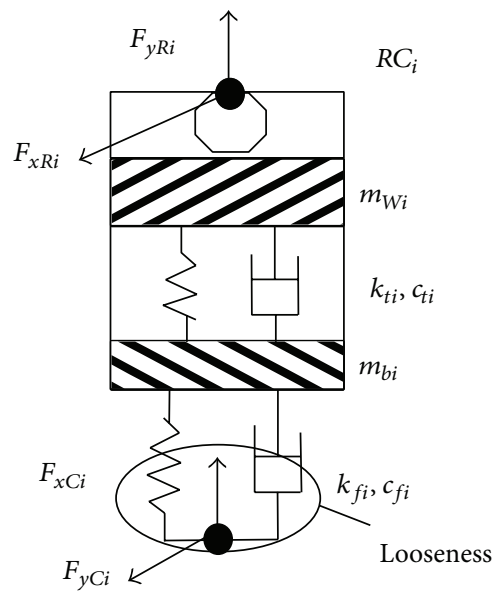

Figure 3: Rotor-casing support.

equation, the motion equations of beam element relative to the fixed coordinate system can be obtained:

$$
\left(\mathbf{M}_{T e}+\mathbf{M}_{R e}\right) \ddot{\mathbf{q}}_{e}+\left(-\omega \mathbf{G}_{e}\right) \dot{\mathbf{q}}_{e}+\left(\mathbf{K}_{B e}-\mathbf{K}_{A e}\right) \mathbf{q}_{e}=\mathbf{Q}_{e},
$$


where $\mathbf{Q}_{e}$ is the generalized external force vector; $\mathbf{M}_{T e}$ and $\mathbf{M}_{R e}$ are, respectively, the mass matrix and the mass inertia matrix; $\mathbf{G}_{e}$ is gyroscopic matrix; $\mathbf{K}_{B e}$ are the element's bending and shear stifness matrix; and $\mathbf{K}_{A e}$ is the element's tensile stifness matrix. These matrixes can be found in the literature [15].

The rotor system's motion equation through the element's motion equations can be obtained, which is

$$
\left(\mathbf{M}_{s}\right) \ddot{\mathbf{q}}_{s}+\left(\mathbf{C}_{s}-\omega \mathbf{G}_{s}\right) \dot{\mathbf{q}}_{s}+\mathbf{K}_{s} \mathbf{q}_{s}=\mathbf{Q}_{s},
$$

where $\mathbf{Q}_{s}$ is the generalized external force vector; $\mathbf{M}_{s}$ is the mass matrix; $\mathbf{G}_{s}$ is gyroscopic matrix; $\mathbf{K}_{s}$ is the stiffness matrix of the system; and $\mathbf{C}_{s}$ is the damping matrix of the system.

In this paper, $\mathbf{C}_{s}$ is assumed to be proportional damping matrix, that is, $\mathbf{C}_{s}=\alpha_{0} \mathbf{M}_{s}+\alpha_{1} \mathbf{K}_{s}$, of which, $\alpha_{0}$ and $\alpha_{1}$ are constants. Because the $i$ th order damping ratio is

$$
\xi_{i}=\frac{1}{2}\left(\frac{\alpha_{0}}{\omega_{i}}+\alpha_{1} \omega_{i}\right),
$$

obviously, after any two natural frequencies and damping ratios of the rotor are acquired by modal experiment, $\alpha_{0}$ and $\alpha_{1}$ can be solved through (5), and the system's damping ratio matrix $\mathbf{C}_{s}$ can be obtained.

2.2.2. Casing Model. In general, the casing finite element model can be constructed by the beam element, conical shell element, and surface shell element. However the casing is a shell structure, and its vibration modal has many forms whose circumferential wave number is $0,1,2, \ldots$, and so on. However, when the casing couples with the rotor, only the modal of wave number 1 appears, and the cross-section of rotor does not deform. Therefore, the casing can be constructed by using the common beam element which does not rotate [15].

In this paper, the casing is modeled as a beam which does not rotate, like the rotor modeling, by means of finite element modeling method the differential equation of motion of casing is

$$
\left(\mathbf{M}_{c}\right) \ddot{\mathbf{q}}_{c}+\mathbf{C}_{c} \dot{\mathbf{q}}_{c}+\mathbf{K}_{c} \mathbf{q}_{c}=\mathbf{Q}_{c}
$$

where $\mathbf{Q}_{c}$ is the generalized excitation force vector; $\mathbf{M}_{c}$ is the mass matrix of casing; $\mathbf{K}_{c}$ is the stiffness matrix of casing; $\mathbf{C}_{c}$ is the damper matrix of casing; likewise, $\mathbf{C}_{s}$ is assumed to be proportional damping matrix.

\subsubsection{Discrete Support Model}

(1) The Support Connection between Rotor and Casing. Each support connection between rotor and casing $R C_{i}(i=$ $1,2, \ldots, N)$ includes ball bearing and bearing housing. Suppose that $m_{w i}$ is the outer mass of bearing; $m_{b i}$ is the mass of bearing housing; $k_{t i}$ is the support stiffness between outer race and bearing house; $c_{t i}$ is the damping coefficient between outer race and the bearing housing; and $k_{f i}, c_{f i}$ are, respectively, the support stiffness and damping coefficient between the casing and the bearing housing. As shown in
Figure 3, $F_{y R i}$ and $F_{x R i}$ are the force of rotor acting on the support $R C_{i}$ and the $F_{y C i}$ and $F_{x C i}$ are the force of casing acting on support $R C_{i}$. It is assumed that support $R C_{i}$ is connected with the $m$ th node of rotor and the $n$th node of casing. In this paper, the looseness fault between the bearing house and casing is considered.

In this paper, the bearing outer ring is supposed to be fixed on the bearing housing, and the inner ring is fixed on the rotating shaft. Assume that the displacements of the $m$ th node of rotor are $x_{R m}$ and $y_{R m}$; let $x=x_{R m}-x_{w i}, y=y_{R m}-y_{w i}$; according to Chen et al. [16], the ball force can be expressed as

$$
\begin{aligned}
F_{x R i}= & \sum_{j=1}^{N} C_{b}\left(x \cos \theta_{j}+y \sin \theta_{j}-r_{0}\right)^{3 / 2} \\
& \times H\left(x \cos \theta_{j}+y \sin \theta_{j}-r_{0}\right) \cos \theta_{j}, \\
F_{y R i}= & \sum_{j=1}^{N} C_{b}\left(x \cos \theta_{j}+y \sin \theta_{j}-r_{0}\right)^{3 / 2} \\
& \times H\left(x \cos \theta_{j}+y \sin \theta_{j}-r_{0}\right) \sin \theta_{j} .
\end{aligned}
$$

In the formula, $C_{b}$ is the Hertzian contact stiffness and it can be obtained from the nonlinear Hertzian contact elastic analysis of the inner race, the outer race and the balls $H(\cdot)$ are the Heaviside function; when the function independent variable is greater than 0 , function value is 1 ; otherwise it is 0. $\theta_{j}$ is the $j$ th ball's angle position, that is, $\theta_{j}=\omega_{\text {Cage }} \times t+$ $\left(2 \pi / N_{b}\right)(j-1), j=1,2, \ldots, N_{b}$, where $N_{b}$ is the number of balls. $\omega_{\text {Cage }}$ is the cage's rotating speed. Suppose that the outer race radius is $R$, the inner ring radius is $r, \omega_{\text {Cage }}=(\omega \times r) /(R+$ $r$ ), and $\omega$ is shaft rotating angular velocity.

Therefore, the bearing outer race's differential equation of motion is

$$
\begin{aligned}
m_{w i} \ddot{x}_{w i}+k_{t i}\left(x_{w i}-x_{b i}\right)+F_{d x i} & =F_{x R i}, \\
m_{w i} \ddot{y}_{w i}+k_{t i}\left(y_{w i}-y_{b i}\right)+F_{d y i} & =F_{y R i}-m_{w i} g, \\
& i=1,2, \ldots, N,
\end{aligned}
$$

where $F_{d x i}$ and $F_{d y i}$ are damping forces; if the viscous damping is considered, then

$$
F_{d x i}=c_{t i}\left(\dot{x}_{w i}-\dot{x}_{b i}\right), \quad F_{d y i}=c_{t i}\left(\dot{y}_{w i}-\dot{y}_{b i}\right) .
$$

(2) The Coupling Connection between Rotor and Rotor. Assume that the coupling connection $R R C_{k}(k=1,2, \ldots, N)$ connects the $i$ th node of left rotor and the $j$ th node of right rotor, the radial stiffness of coupling is $k_{R r}$, the angular stiffness is $k_{R \alpha}$, the radial damping is $c_{R r}$, and the angular damping is $c_{R \alpha}$. Let the generalized displacements of the $i$ th node of the left rotor be $x_{R L i}, y_{R L i}, \phi_{R L i}, \psi_{R L i}$; the velocities are $\dot{x}_{R L i}, \dot{y}_{R L i}, \dot{\phi}_{R L i}, \dot{\psi}_{R L i}$; let the $j$ th node displacements of the right rotor be $x_{R R j}, y_{R R j}, \phi_{R R j}, \psi_{R R j}$; the velocities are $\dot{x}_{R R j}, \dot{y}_{R R j}, \dot{\phi}_{R R j}, \dot{\psi}_{R R j}$. Then, the forces and the moments which act on the $i$ th node of left rotor $F_{R x i}, F_{R y i}, M_{R x i}, M_{R y i}$ 
and the forces and the moments $F_{R x j}, F_{R y j}, M_{R x j}, M_{R y j}$ for the $j$ th node of right rotor are

$$
\begin{gathered}
F_{R x i}=k_{R r}\left(x_{R R j}-x_{R L i}\right)+c_{R r}\left(\dot{x}_{R R j}-\dot{x}_{R L i}\right), \\
F_{R y i}=k_{R r}\left(y_{R R j}-y_{R L i}\right)+c_{R r}\left(\dot{y}_{R R j}-\dot{y}_{R L i}\right), \\
M_{R x i}=k_{R \alpha}\left(\phi_{R R j}-\phi_{R L i}\right)+c_{R \alpha}\left(\dot{\phi}_{R R j}-\dot{\phi}_{R L i}\right), \\
M_{R y i}=k_{R \alpha}\left(\psi_{R R j}-\psi_{R L i}\right)+c_{R \alpha}\left(\dot{\psi}_{R R j}-\dot{\psi}_{R L i}\right), \\
F_{R x j}=-F_{R x i}, \\
F_{R y j}=-F_{R y i}, \\
M_{R x j}=-M_{R x i}, \\
M_{R y j}=-M_{R y i} .
\end{gathered}
$$

(3) The Bearing Housing Looseness Model. Generally, symmetric stiffness and asymmetrical stiffness models $[4,5]$ are considered in the looseness fault model. But presently the looseness stiffness model has no universal definition. In this paper, the simulation analysis is made in two conditions. $k_{f 0}$ is assumed to be the equivalent stiffness between the bearing housing and the casing. Under the condition of relative displacement, piecewise linear stiffness between the bearing housing and the casing is considered in this paper; $\delta$ is assumed to be the looseness amounts of the bearing housing. The piecewise nonlinear stiffness $k_{f}$ can be expressed as follows.

Asymmetric stiffness:

$$
k_{f}= \begin{cases}k_{f 0} & \left(x_{b}-x_{c}>\delta\right) \\ \frac{k_{f 0}}{5} & \left(0 \leq x_{b}-x_{c} \leq \delta\right) \\ 5 k_{f 0} & \left(x_{b}-x_{c}<0\right) ;\end{cases}
$$

symmetric stiffness:

$$
k_{f}= \begin{cases}k_{f 0} & \left(x_{b}-x_{c}>\delta\right) \\ \frac{k_{f 0}}{5} & \left(0 \leq x_{b}-x_{c} \leq \delta\right) \\ k_{f 0} & \left(x_{b}-x_{c}<0\right),\end{cases}
$$

where $x_{b}$ is the displacement of the bearing housing and $x_{c}$ is the displacement of the casing; the stiffness directions in $x$ direction and $y$ direction are the same. The formulas are appied in horizontal and vertical directions.

2.2.4. Elastic Support (Installation Node) between Casing and Base. The elastic connection between casing and base $C B_{k}$ $(k=1,2, \ldots, N)$ connects the $i$ th node of casing and the base, the support stiffness is $k_{C}$, and the damping is $c_{C}$. Let the displacements of the $i$ th node of casing be $x_{C i}, y_{C i}$ and the velocities $\dot{x}_{C i}, \dot{y}_{C i}$; then the forces acting on the $i$ th node of casing $F_{C x i}$ and $F_{C y i}$ are

$$
\begin{aligned}
& F_{C x i}=-k_{C} x_{C i}-c_{C} \dot{x}_{C i}, \\
& F_{C y i}=-k_{C} y_{C i}-c_{C} \dot{y}_{C i} .
\end{aligned}
$$

TABLE 1: Unit number of rotors and casings.

\begin{tabular}{lccc}
\hline Fan rotor & Compressor rotor & Turbine rotor & Casing \\
\hline 11 & 10 & 11 & 24 \\
\hline
\end{tabular}

\subsection{Solution of Finite Element Rotor-Support-Casing Coupling} Dynamic Model. Because the number of DOFs in the finite element rotor-support-casing coupling dynamic model is very large, in addition, there are a lot of strong nonlinear factors, in this paper a combination time integration approach is used to solve system's responses, which combines the implicit Newmark- $\beta$ method and the improved explicit Newmark- $\beta$ method (Zhai [17]). This finite element rotorsupport coupling dynamic solution procedure is shown in Figure 4.

The merits of combination methods are described as follows: (1) the Newmark- $\beta$ method is used to solve the rotor and casing finite element model, and the Zhai method is used to solve the lumped parameter support models; therefore, the combination method is very fit for solving coupling system; (2) the enormous matrix need not be formed, and the matrixes of the rotors and the casings need not be combined into a large matrix; therefore, the computation efficiency is improved greatly.

\section{Looseness Fault Analysis}

3.1. Dynamic Model Parameters. The finite element parameters of the rotor, the casing, and the connection parameters of rotor-casing-bearing system are shown in Tables $1,2,3,4,5$, 6 , and 7.

\subsection{Calculation Condition}

(1) The looseness fault between the bearing housing and the casing in a horizontal and vertical direction is considered, and their looseness amounts are all $1.0 \mu \mathrm{m}$.

(2) The looseness fault in the fan fulcrum and the front compressor fulcrum is considered.

(3) The output is the casing horizontal and the vertical vibration acceleration response in front of compressor fulcrum.

(4) The speed range is 10000-30000 rpm.

3.3. Critical Speed Analysis. Figure 5 shows the amplitudespeed curves of the bearing housing $S_{1}$ lateral acceleration, the casing lateral acceleration at the ninth node, and the compressor rotor lateral displacement at the first node under imbalance fault. As can be seen from the figures, the firstorder and the second-order critical speeds are $17300 \mathrm{rpm}$ and $18500 \mathrm{rpm}$, respectively.

3.4. Autocorrelation Method. Autocorrelation technology can be used in signal filter when the signal is weak and sound energy is large, which is effective to detect weak 
TABLE 2: Parameters of rotors.

\begin{tabular}{|c|c|c|c|c|c|}
\hline Parameters & Disk $P_{1}$ & $\operatorname{Disk} P_{2}$ & $\operatorname{Disk} P_{3}$ & $\operatorname{Disk} P_{4}$ & Disk $P_{5}$ \\
\hline Mass $m_{p}(\mathrm{~kg})$ & 3.88 & 1.41 & 5.17 & 10.28 & 10.28 \\
\hline Cross-polar inertia $J_{p d}\left(\mathrm{~kg} \cdot \mathrm{m}^{2}\right)$ & 0.03 & 0.003 & 0.03 & 0.05 & 0.05 \\
\hline Cross-equator inertia $J_{d d}\left(\mathrm{~kg} \cdot \mathrm{m}^{2}\right)$ & 0.015 & 0.0015 & 0.015 & 0.025 & 0.025 \\
\hline Elastic modulus $E(\mathrm{~Pa})$ & 2.07 & 2.07 & 2.07 & 2.07 & 2.07 \\
\hline Poisson's ratio $\mu$ & 0.3 & 0.3 & 0.3 & 0.3 & 0.3 \\
\hline Density $\rho\left(\mathrm{kg} / \mathrm{m}^{3}\right)$ & $7.8 \times 10^{3}$ & $7.8 \times 10^{3}$ & $7.8 \times 10^{3}$ & $7.8 \times 10^{3}$ & $7.8 \times 10^{3}$ \\
\hline Proportion damping ratio $\alpha_{0}$ & 5 & 5 & 5 & 5 & 5 \\
\hline Proportion damping ratio $\alpha_{1}$ & 1.35 & 1.35 & 1.35 & 1.35 & 1.35 \\
\hline
\end{tabular}

TABle 3: Parameters of casings.

\begin{tabular}{lccccc}
\hline Wall thickness $/ \mathrm{mm}$ & $\begin{array}{c}\text { Elastic modulus } \\
E(\mathrm{~Pa})\end{array}$ & $\begin{array}{c}\text { Density } \rho \\
\left(\mathrm{kg} / \mathrm{m}^{3}\right)\end{array}$ & Poisson's ratio $\mu$ & $\begin{array}{c}\text { Proportion } \\
\text { damping ratio } \alpha_{0}\end{array}$ & $\begin{array}{c}\text { Proportion } \\
\text { damping ratio } \alpha_{1}\end{array}$ \\
\hline 15 & $2.07 \times 10^{11}$ & $7.8 \times 10^{3}$ & 0.3 & 5 & $1.35 \times 10^{-5}$ \\
\hline
\end{tabular}

TABLE 4: Parameters of ball bearing.

\begin{tabular}{lccccccc}
\hline $\begin{array}{l}\text { Rolling } \\
\text { bearing }\end{array}$ & $\begin{array}{c}\text { Outer raceway } \\
\text { radius } R / \mathrm{mm}\end{array}$ & $\begin{array}{c}\text { Inner raceway } \\
\text { radius } r / \mathrm{mm}\end{array}$ & $\begin{array}{c}\text { Ball number } \\
N_{b}\end{array}$ & $\begin{array}{c}\text { Contact stiffness } \\
C_{b} /\left(\mathrm{N} / \mathrm{m}^{3 / 2}\right)\end{array}$ & $\begin{array}{c}\text { Bearing } \\
\text { clearance } r_{0} / \mathrm{um}\end{array}$ & $\begin{array}{c}\text { Outer mass } m_{w} \\
(\mathrm{~kg})\end{array}$ & $\begin{array}{c}\text { Bearing carrier } \\
\mathrm{mass} m_{b}(\mathrm{~kg})\end{array}$ \\
\hline$B_{1}$ & 39.5 & 29 & 13 & $12.4 \times 10^{9}$ & 0 & 2 & 10 \\
$B_{2}$ & 39.5 & 29 & 13 & $12.4 \times 10^{9}$ & 0 & 2 & 10 \\
$B_{3}$ & 32 & 17 & 14 & $11.9 \times 10^{9}$ & 0 & 2 & 10 \\
$B_{4}$ & 32 & 17 & 14 & $11.9 \times 10^{9}$ & 0 & 2 & 10 \\
\hline
\end{tabular}

TABLE 5: Support parameters of rotor-casing.

\begin{tabular}{lcccccc}
\hline Supports & Node of rotor & Casing (node) & $k_{t}(\mathrm{~N} / \mathrm{m})$ & $c_{t}(\mathrm{~N} \cdot \mathrm{s} / \mathrm{m})$ & $k_{f}(\mathrm{~N} / \mathrm{m})$ & $c_{f}(\mathrm{~N} \cdot \mathrm{s} / \mathrm{m})$ \\
\hline$R C_{1}$ & 3 & 2 & $1 \times 10^{8}$ & 2000 & $1 \times 10^{8}$ \\
$R C_{2}$ & 1 & 9 & $1 \times 10^{8}$ & 2000 & $1 \times 10^{8}$ \\
$R C_{3}$ & 11 & 16 & $1 \times 10^{8}$ & 2000 & $1 \times 10^{8}$ \\
$R C_{4}$ & 8 & 22 & $1 \times 10^{8}$ & 2000 & $1 \times 000$ \\
\hline
\end{tabular}

TABLE 6: Spring collection parameters of rotor-casing.

\begin{tabular}{lcccccc}
\hline Collection & Node of rotor & Casing (node) & $k_{g x}(\mathrm{~N} / \mathrm{m})$ & $c_{g x}(\mathrm{~N} \cdot \mathrm{s} / \mathrm{m})$ & $k_{g y}(\mathrm{~N} / \mathrm{m})$ & $c_{g y}(\mathrm{~N} \cdot \mathrm{s} / \mathrm{m})$ \\
\hline$R C_{1}$ & 6 & 4 & $1 \times 10^{8}$ & 0 & $1 \times 10^{8}$ & 0 \\
\hline
\end{tabular}

TABLE 7: Collection parameters of casing-base.

\begin{tabular}{lccccc}
\hline Supports & $\begin{array}{c}\text { Node of } \\
\text { rotor }\end{array}$ & $\begin{array}{c}\text { Casing } \\
(\text { node })\end{array}$ & $k_{t}(\mathrm{~N} / \mathrm{m})$ & $c_{t}(\mathrm{~N} \cdot \mathrm{s} / \mathrm{m})$ & $k_{f}(\mathrm{~N} / \mathrm{m})$ \\
\hline$C B_{1}$ & 8 & $1 \times 10^{9}$ & $1 \times 10^{5}$ & 2000 & 0 \\
$C B_{2}$ & 23 & $1 \times 10^{9}$ & $1 \times 10^{5}$ & 2000 & 0 \\
\hline
\end{tabular}

periodic signal ingredients in the rotor system and extract the interested frequency components and multiple frequency components.

Because the aeroengine rotor vibration signal is periodic, autocorrelation time domain monitoring method can improve the ability of monitoring weak periodic signal effectively under the condition of the sinusoidal signal frequency position. The periodic signal which is buried in noise can be extracted and the detected signal amplitude has higher precision. The steps are described as follows.

(1) Intercepting $2 \mathrm{~N}$ points from stationary random signal $x(n), x_{2 N}(n)$ can be obtained and then using FFT to it, thus $X_{2 N}(k)$ can be obtained.

(2) Dividing the square of the amplitude of $X_{2 N}(k)$ by $N$, thus $\left|X_{2 N}(k)\right|^{2} / N$ can be obtained.

(3) Using IFFT in $\left|X_{2 N}(k)\right|^{2} / N$, its correlation function can be obtained.

3.5. Characteristics of the Bearing Housing $S_{1}$ Acceleration Response, the Casing Acceleration Response, and the Rotor Displacement under the Asymmetric Stiffness Model. Figure 6 


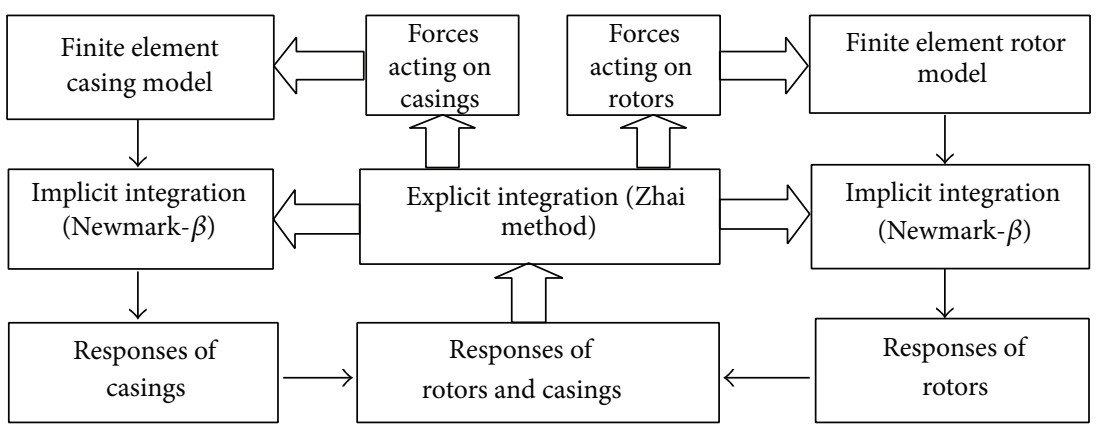

FIGURE 4: Solving flow for rotor-support-casing coupling dynamics.

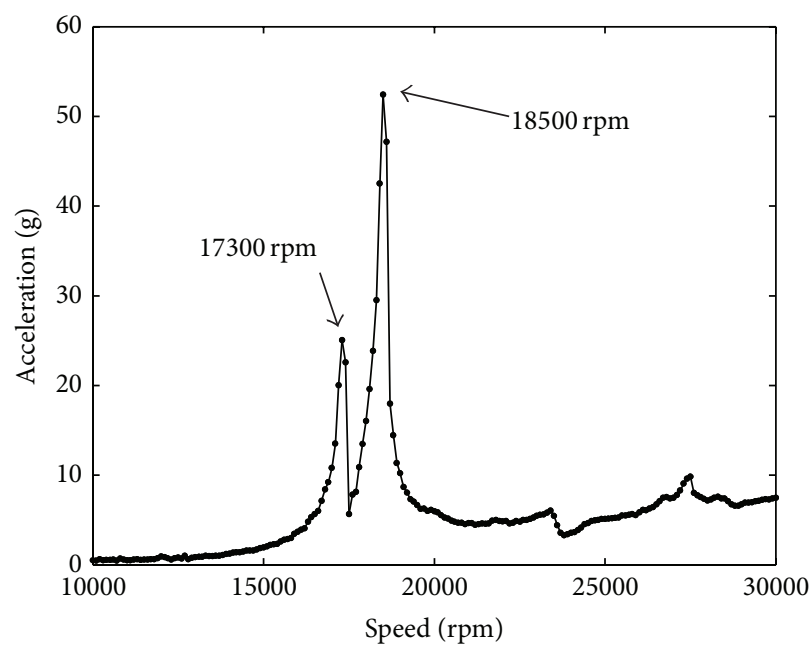

(a) The bearing housing lateral acceleration

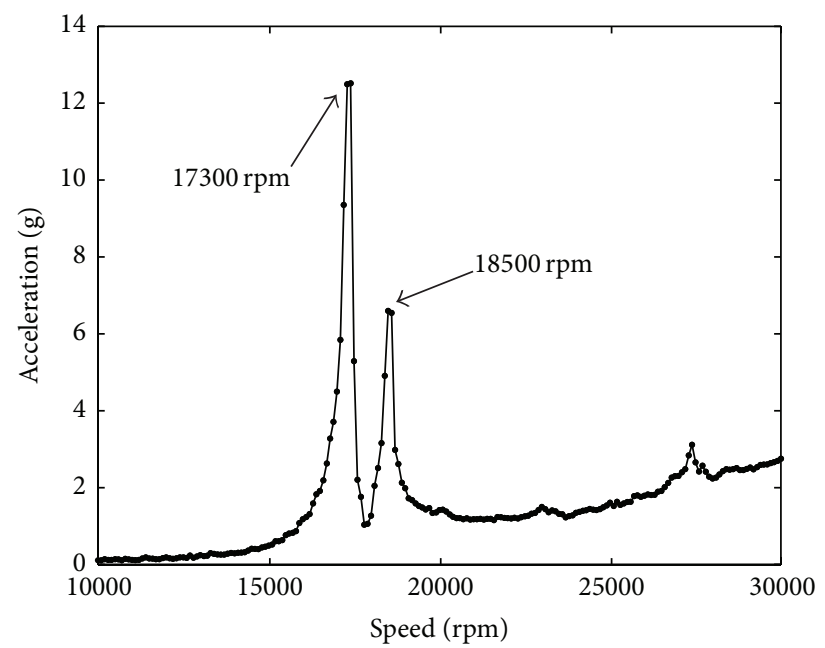

(b) The casing lateral acceleration

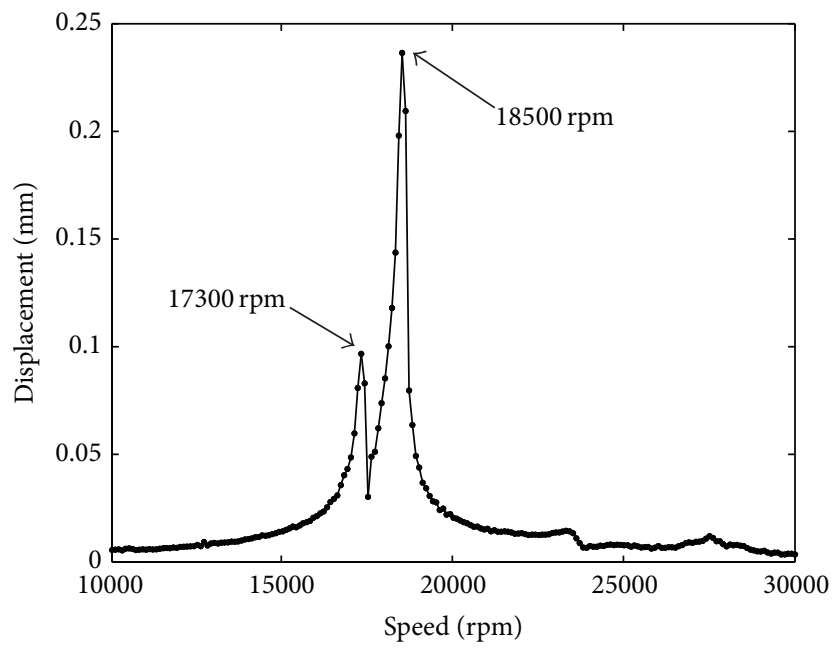

(c) The rotor lateral displacement

FIGURE 5: Amplitude-speed curves of bearing, casing lateral acceleration, and rotor displacement (without looseness).

shows cascade plot of the bearing housing $S_{1}$ lateral acceleration response at different speeds; Figure 7 shows cascade plot of the casing lateral acceleration response at the ninth node at different speeds; Figure 8 shows cascade plot of the compressor rotor lateral displacement at the first node at different speeds, according to the asymmetric stiffness equation (11). Figure 6 shows that subharmonic resonance appears under the high speed and superharmonic resonance appears when the speed is higher than the second-order critical speed. Comparing Figures $6-8$, we find that the multiple frequency 


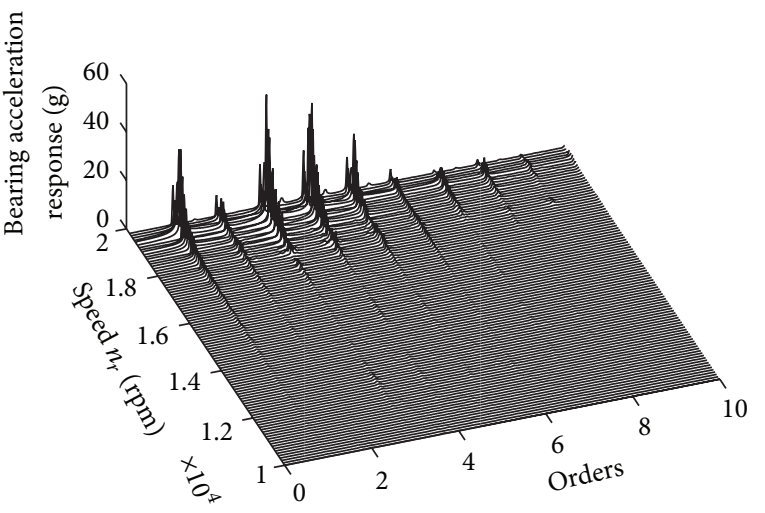

(a) Speeds from $10000 \mathrm{rpm}$ to $20000 \mathrm{rpm}$

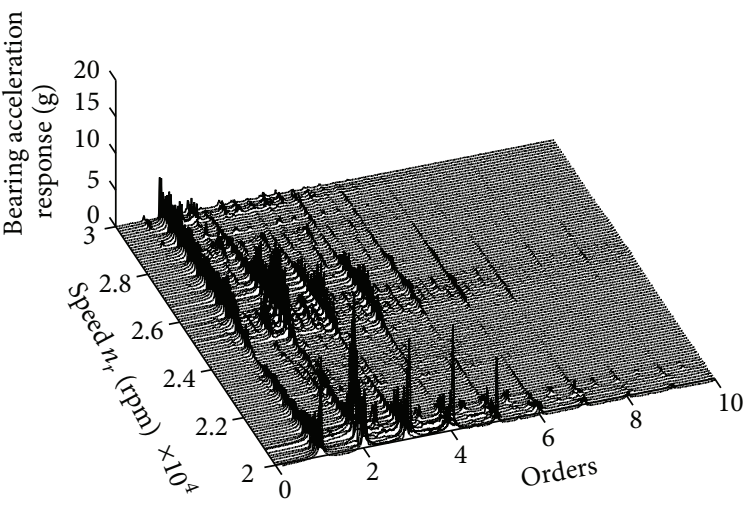

(b) Speeds from $20000 \mathrm{rpm}$ to $30000 \mathrm{rpm}$

Figure 6: Cascade plot of the bearing housing acceleration response at different speeds.

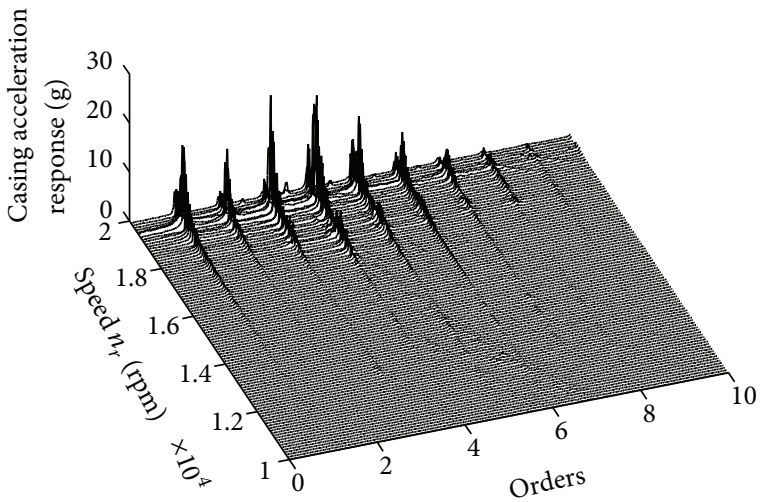

(a) Speeds from $10000 \mathrm{rpm}$ to $20000 \mathrm{rpm}$

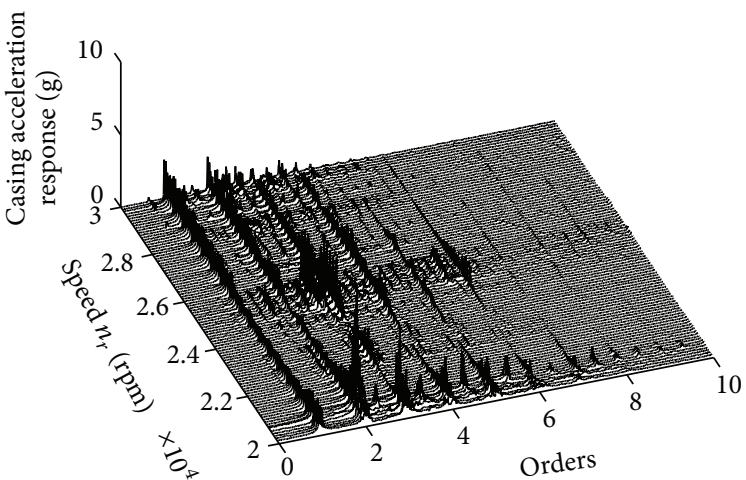

(b) Speeds from $20000 \mathrm{rpm}$ to $30000 \mathrm{rpm}$

Figure 7: Cascade plot of the casing acceleration response at different speeds.

components of the bearing housing $S_{1}$ acceleration response and the casing acceleration is obvious than the multiple frequency components of the rotor displacement response.

Figures 9, 10, and 11 show time domain waveform and spectrum of casing acceleration response at the speeds of $19500 \mathrm{rpm}, 26000 \mathrm{rpm}$, and $30000 \mathrm{rpm}$, which are obtained before and after the noise reduction of autocorrelation. As can be seen from the figures, there are many multiple frequency components and dividing frequency components, which are caused by the looseness fault; the waveforms after the noise reduction of autocorrelation have a typical shock characteristic with the waveform of truncated shape, which is longitudinal asymmetrical one. The casing acceleration time domain waveforms could determine the characteristics of the looseness fault.

Figure 12 shows cascade plot of the bearing housing $S_{1}$ lateral acceleration response at different speeds, according to the symmetric stiffness equation (12). As can be seen from the figures, there are not many multiple frequency components and the looseness fault characteristics would not be obvious. Figure 13 shows the time domain waveform and the spectrum of casing acceleration response at the speed of $25000 \mathrm{rpm}$, which is obtained before and after the noise reduction of autocorrelation. As can be seen from the figures, the spectrum of acceleration response appears double frequency, caused by the looseness fault. As can be seen from the figures, the shock characteristics are not obvious, without the waveform of truncated shape, and many multiple frequency components could not be seen from the spectrum diagram.

\subsection{The Influence of the Looseness Stiffness between the Bearing} Housing $S_{1}$ and the Casing. In order to study the influence of looseness stiffness on the whole aeroengine vibration, the compressor looseness stiffness between the bearing housing $S_{1}$ and the casing is reduced by two times and increased by two times, respectively, and the characteristics of the casing acceleration signal are analyzed.

Figure 14 shows cascade plot of the casing lateral acceleration response at different speeds according to the asymmetric stiffness equation (11), when the looseness stiffness $k_{f 1}$ between the compressor bearing housing $S_{1}$ and the casing is reduced by two times. As can be seen from the figures, there are many multiple frequency components and dividing frequency components, which are caused by the looseness fault. Figure 15 shows time domain waveform and 


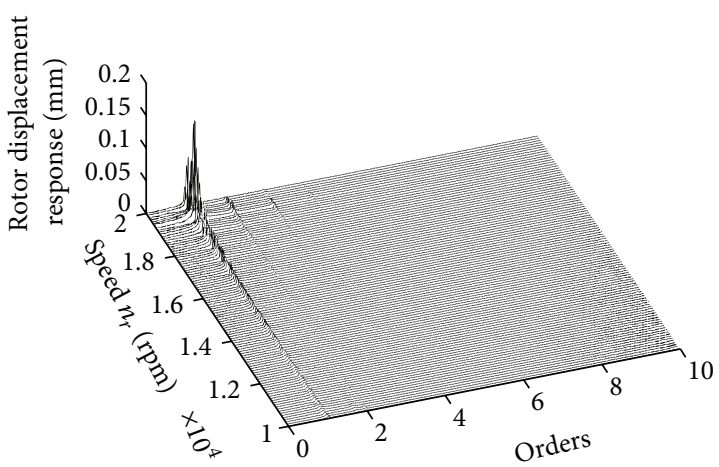

(a) Speeds from $10000 \mathrm{rpm}$ to $20000 \mathrm{rpm}$

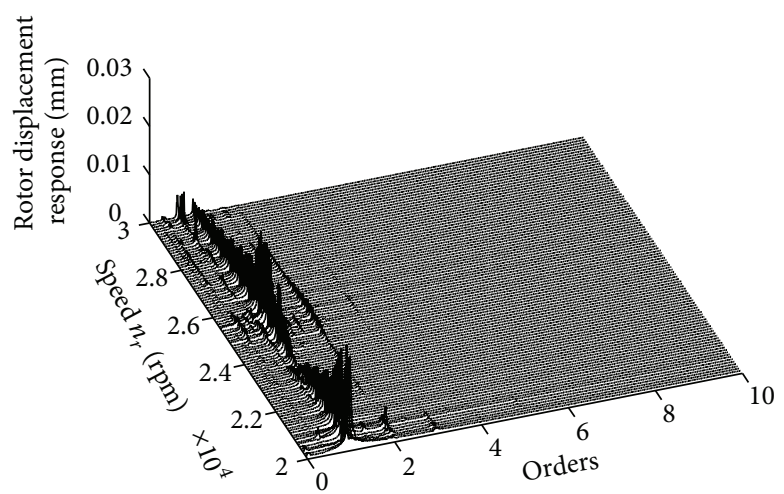

(b) Speeds from $20000 \mathrm{rpm}$ to $30000 \mathrm{rpm}$

FIGURE 8: Cascade plot of the rotor displacement response at different speeds.

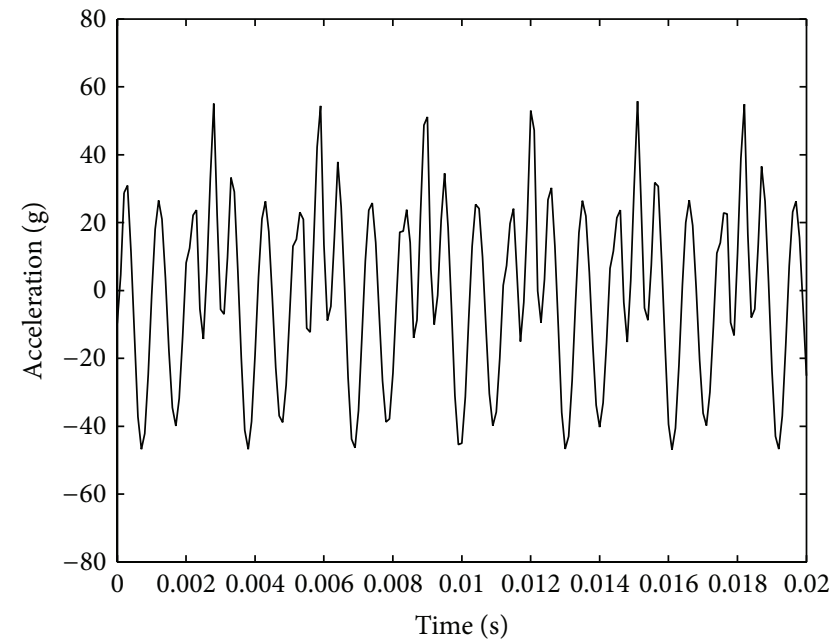

(a) The waveform before the noise reduction

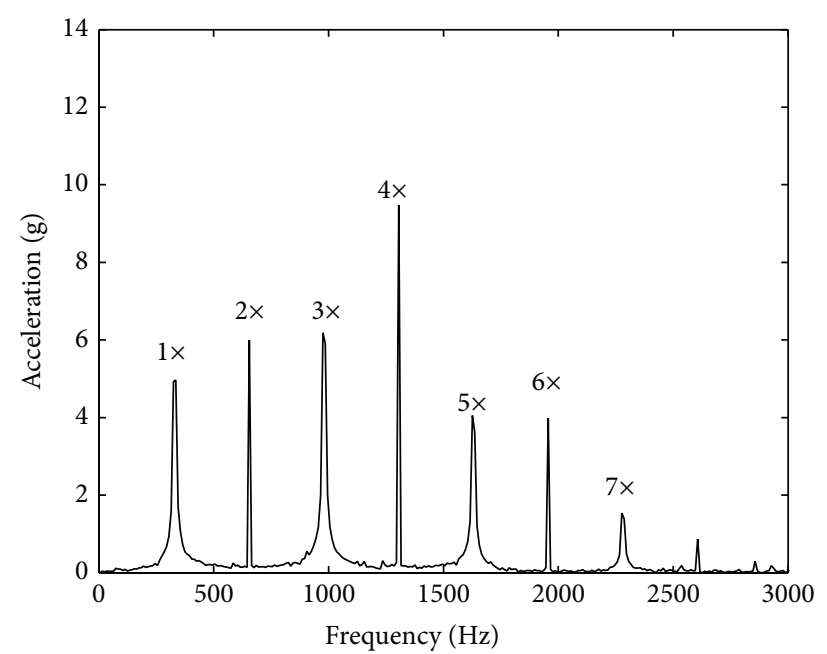

(c) The spectrum before the noise reduction

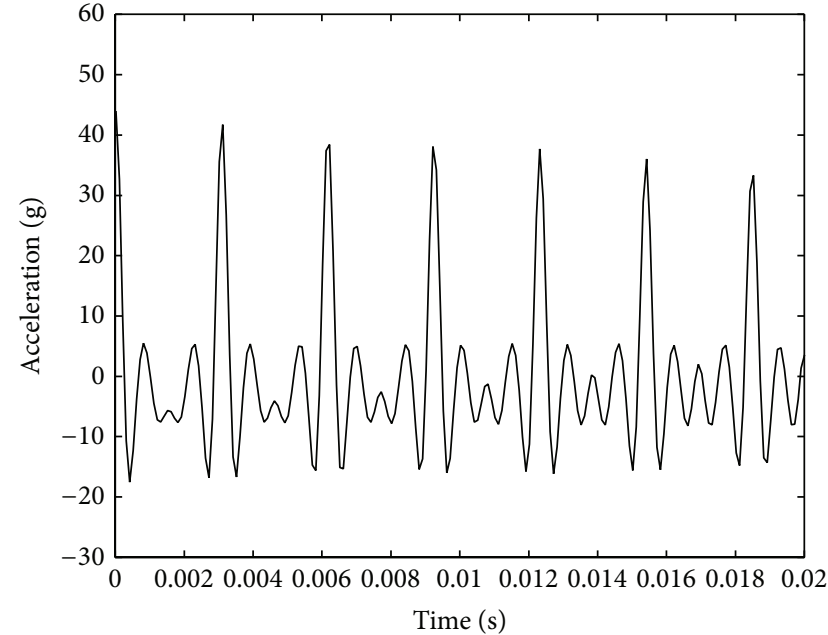

(b) The waveform after the noise reduction

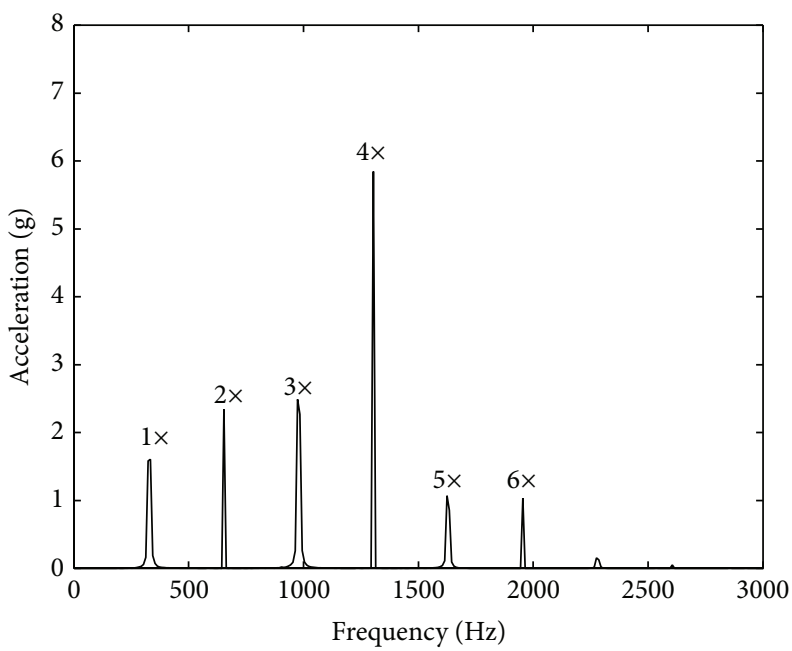

(d) The spectrum after the noise reduction

FIGURE 9: Time domain waveform and frequency spectrum before and after the noise reduction when the rotating speed is $19500 \mathrm{rpm}$. 


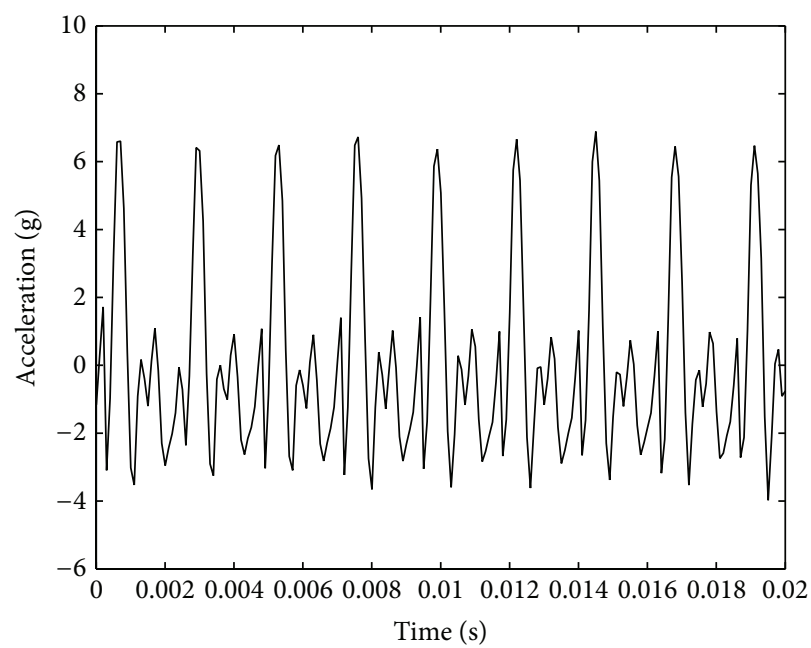

(a) The waveform before the noise reduction

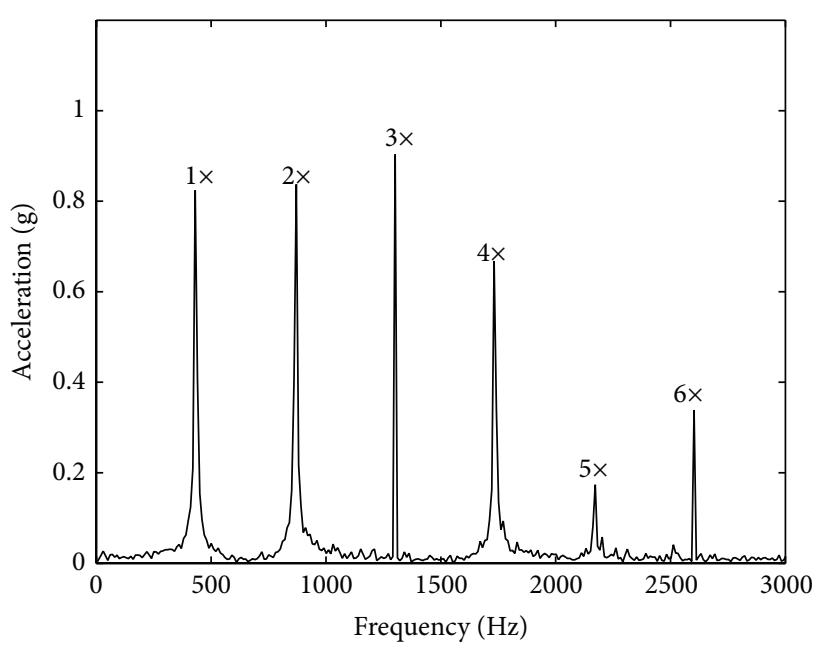

(c) The spectrum before the noise reduction

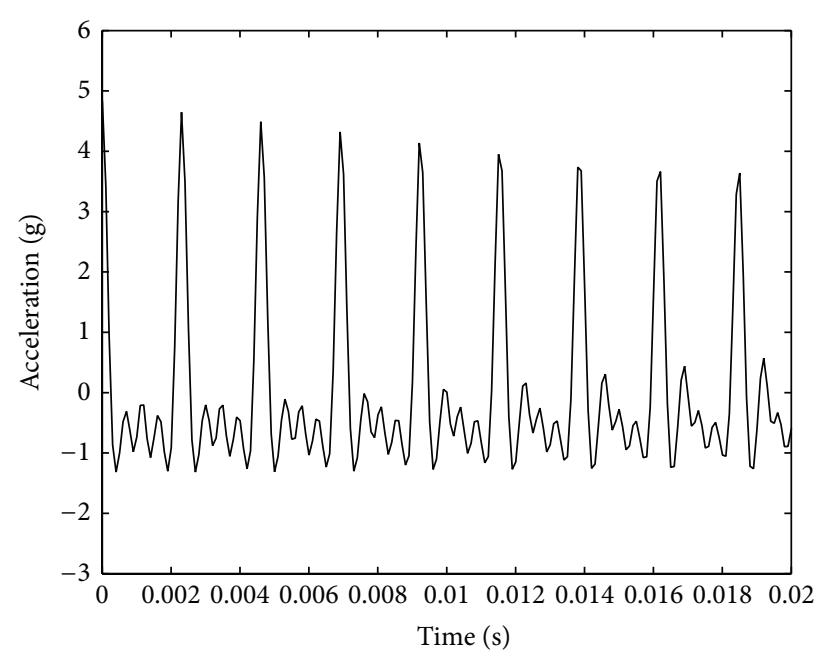

(b) The waveform after the noise reduction

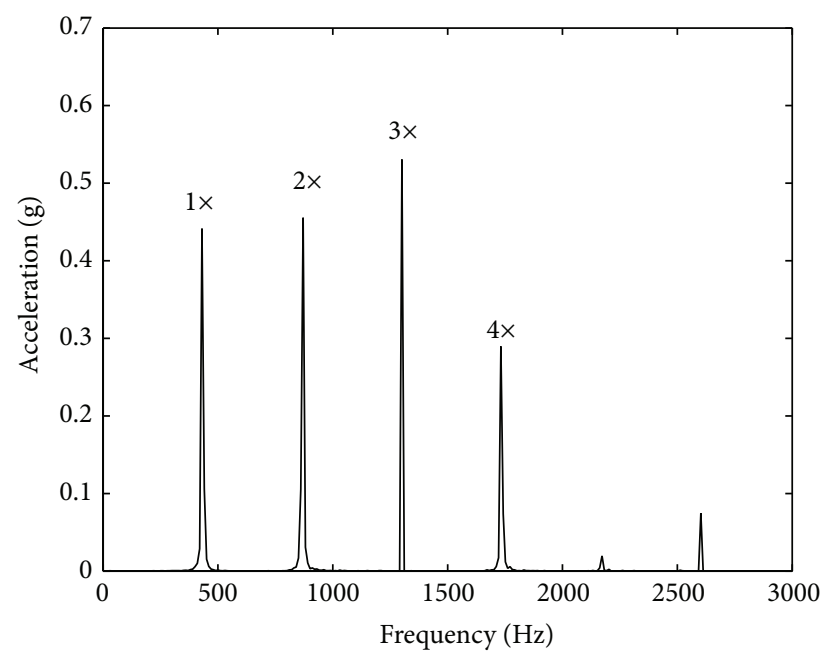

(d) The spectrum after the noise reduction

FIGURE 10: The time domain waveform and frequency spectrum before and after the noise reduction when the rotating speed is $26000 \mathrm{rpm}$.

spectrum of casing acceleration response at the speed of $17000 \mathrm{rpm}$, which is obtained before and after the noise reduction of autocorrelation. As can be seen from the figures, the waveforms after the noise reduction of autocorrelation have a typical shock characteristic, with the waveform of truncated shape, which is longitudinal asymmetrical one. The looseness fault would be judged by the casing acceleration time domain waveforms.

Figure 16 shows cascade plot of the casing lateral acceleration response at different speeds according to the asymmetric stiffness equation (11), when looseness stiffness $k_{f 1}$ between the compressor bearing housing $S_{1}$ and the casing is increased by two times. As can be seen from the figures, there are many multiple frequency components and dividing frequency components, which are caused by the looseness fault. Figure 17 shows the time domain waveform and spectrum of the casing acceleration response at the speed of $21000 \mathrm{rpm}$, which is obtained before and after the noise reduction of autocorrelation. As can be seen from the figures, the waveforms have the characteristic that is a typical shock characteristic, with the waveform of truncated shape, which is longitudinal asymmetrical one. As can be seen from the influence of support stiffness on the looseness fault characteristic, different support stiffness has little effect on the time domain characteristic of the looseness fault, but there is some difference in spectrum; namely, the higher support stiffness will produce much higher multiple frequency components.

\section{Verification and Analysis of the Real Trial Running Data}

Figure 18 shows cascade plot of the real trial running data. The measuring points are the compressor casing horizontal and vertical direction of the compressor fulcrum. As can be seen from the figures, there are many multiple frequency components and dividing frequency components. Figures 19, 20 , and 21 show time domain waveform and spectrum of the casing acceleration response at the speeds of $24000 \mathrm{rpm}$, 


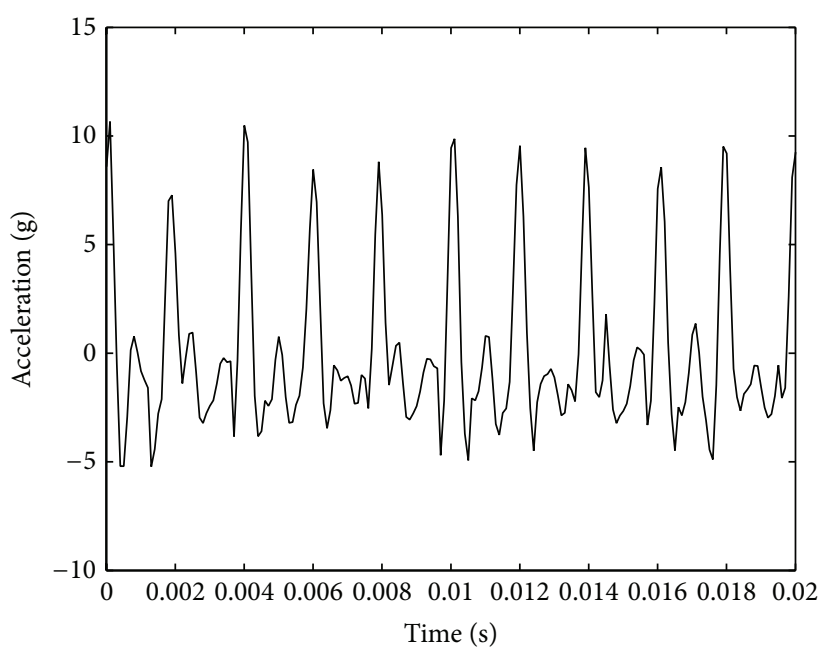

(a) The waveform before the noise reduction

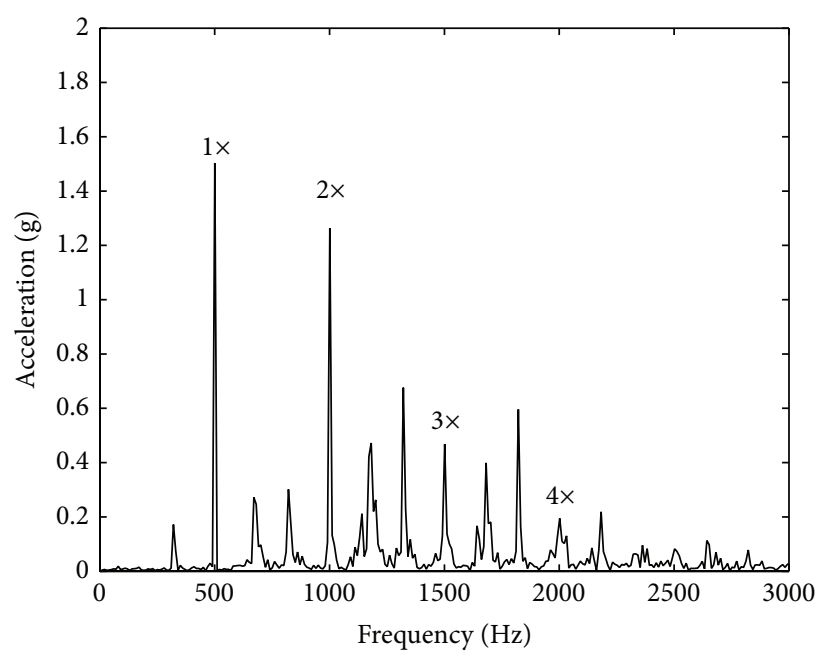

(c) The spectrum before the noise reduction

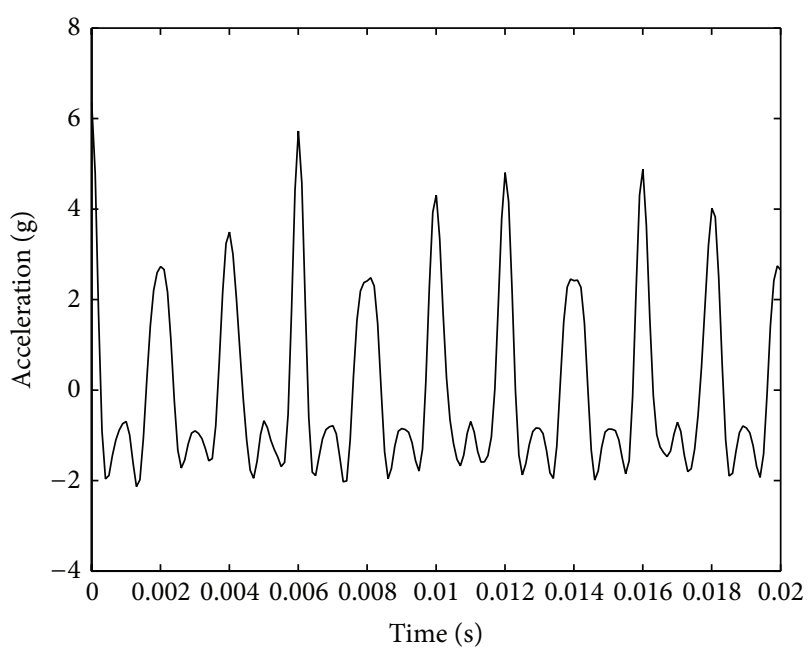

(b) The waveform after the noise reduction

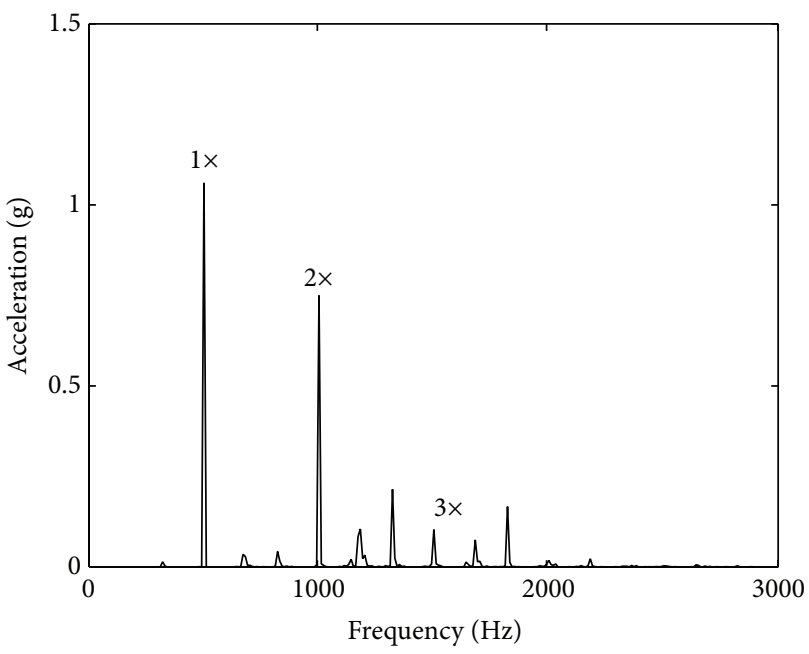

(d) The spectrum after the noise reduction

FIGURE 11: The time domain waveform and frequency spectrum before and after the noise reduction when the rotating speed is $30000 \mathrm{rpm}$.

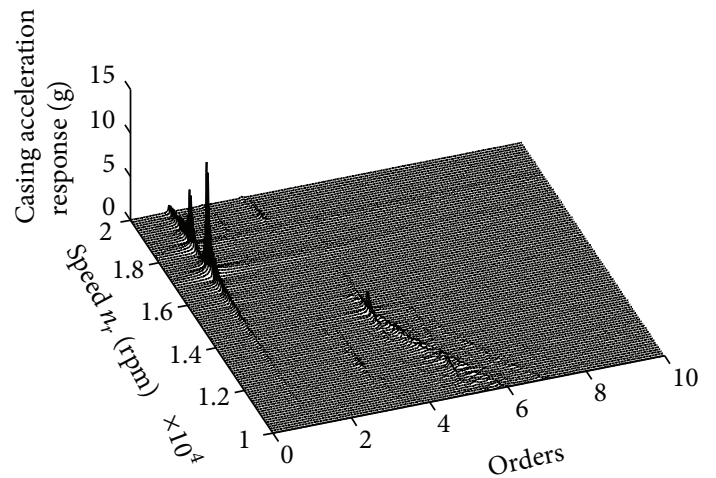

(a) Speeds from $10000 \mathrm{rpm}$ to $20000 \mathrm{rpm}$

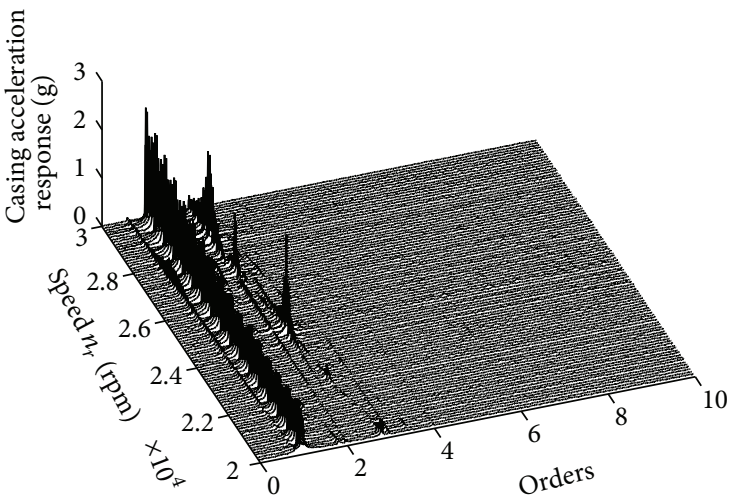

(b) Speeds from $20000 \mathrm{rpm}$ to $30000 \mathrm{rpm}$

FIGURE 12: Cascade plot of the casing acceleration response at different speeds. 


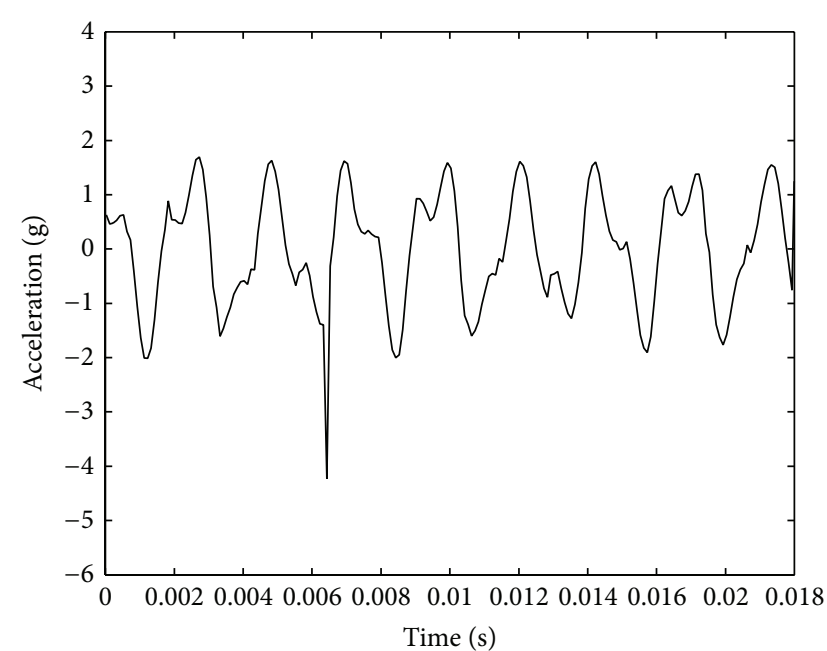

(a) The waveform before the noise reduction

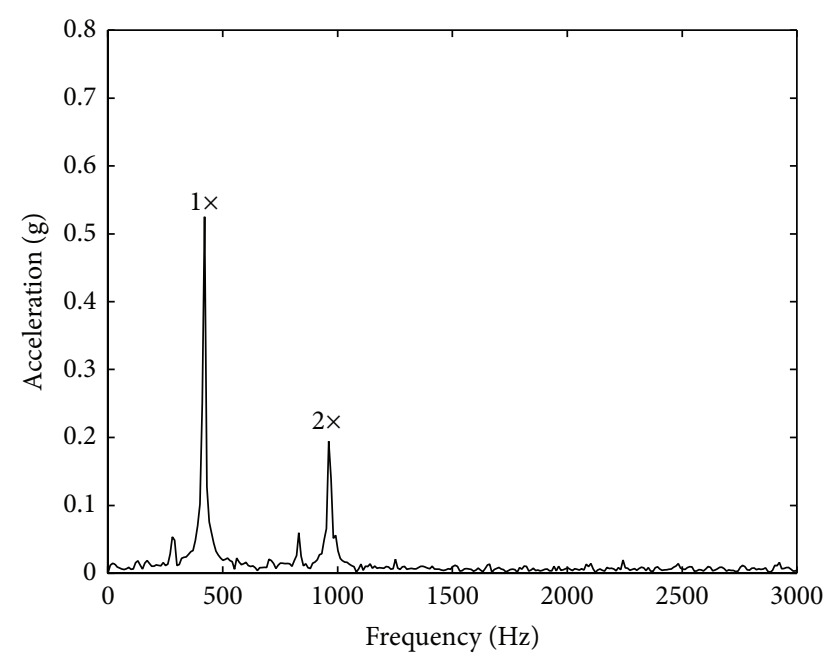

(c) The spectrum before the noise reduction

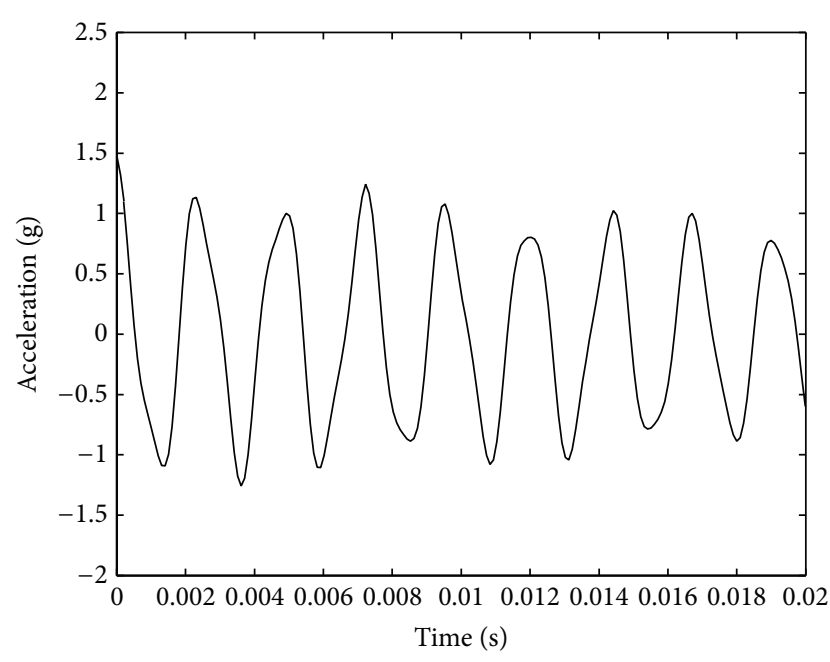

(b) The waveform after the noise reduction

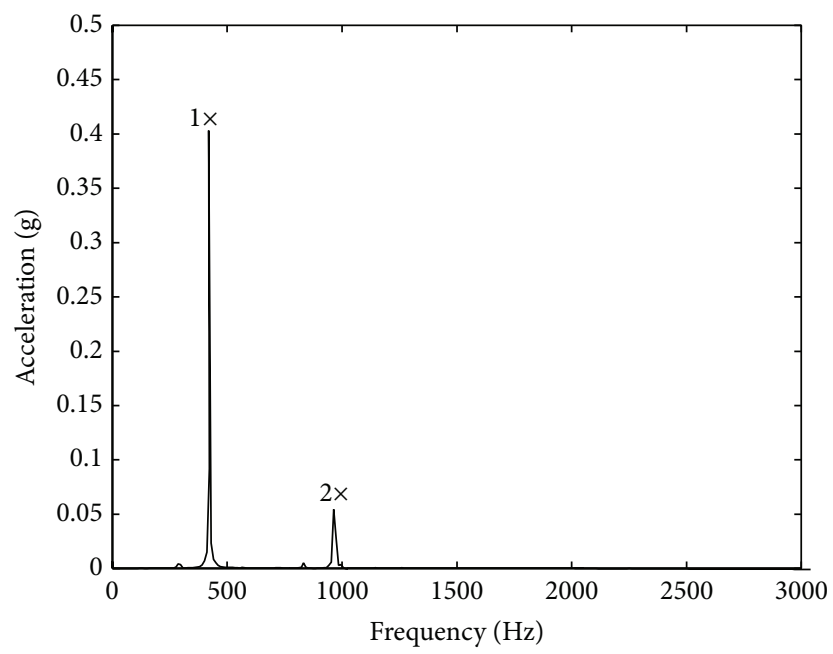

(d) The spectrum after the noise reduction

FIGURE 13: The time domain waveform and frequency spectrum before and after the noise reduction when the rotating speed is $25000 \mathrm{rpm}$.

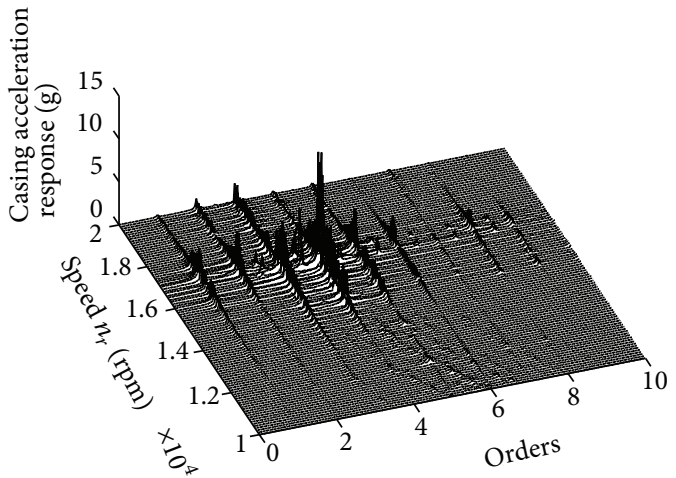

(a) Speeds from $10000 \mathrm{rpm}$ to $20000 \mathrm{rpm}$

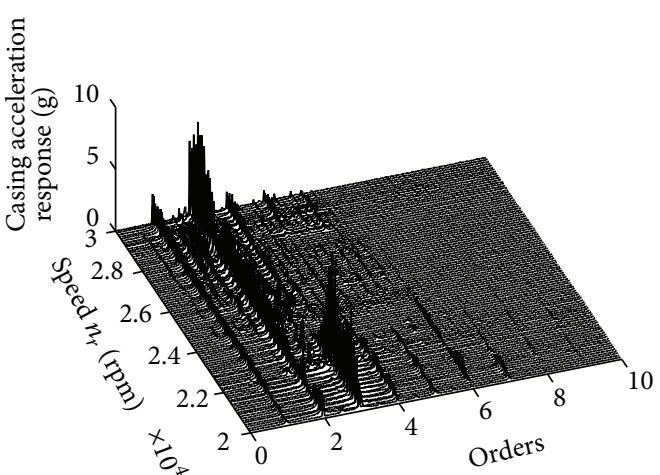

(b) Speeds from $20000 \mathrm{rpm}$ to $30000 \mathrm{rpm}$

FIGURE 14: Cascade plot of the casing acceleration response at different speeds. 


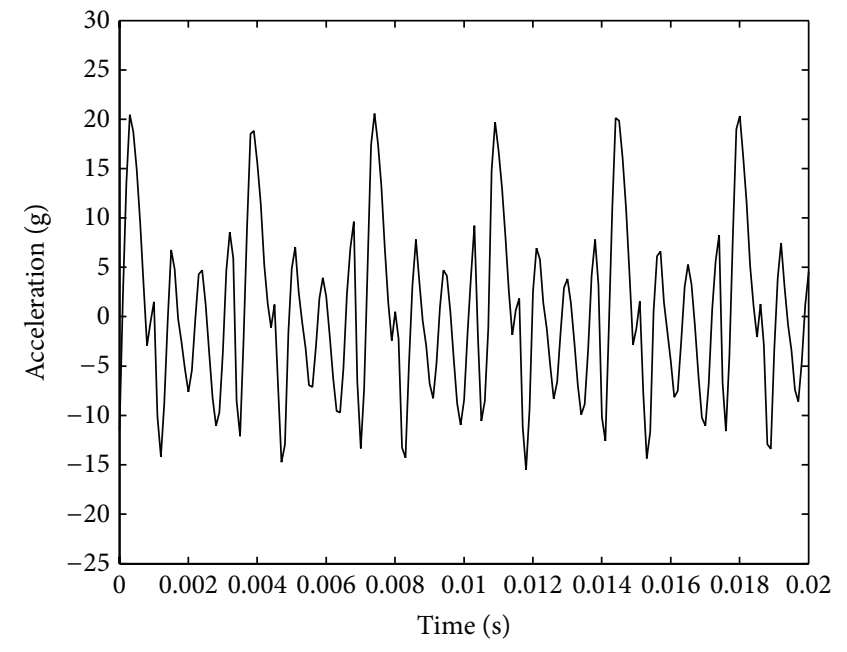

(a) The waveform before the noise reduction

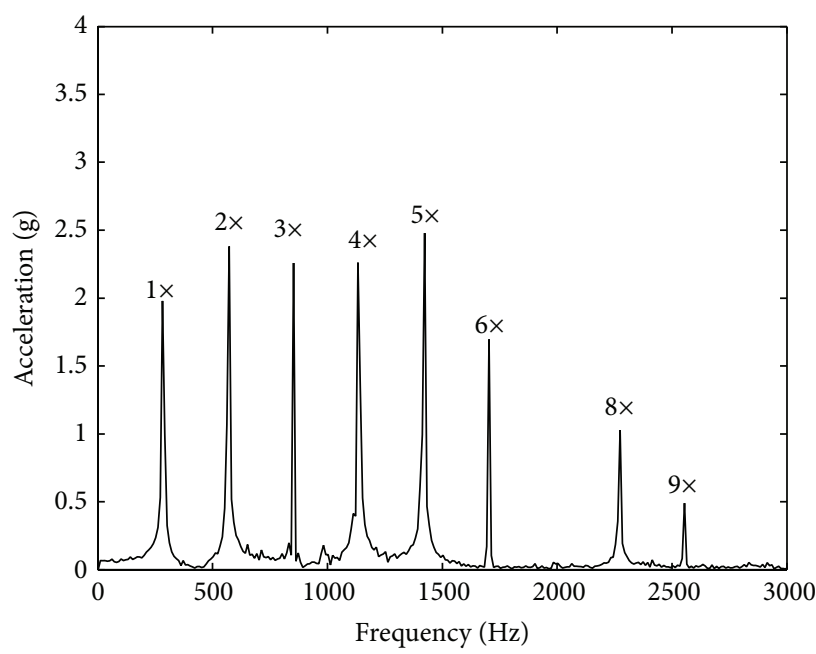

(c) The spectrum before the noise reduction

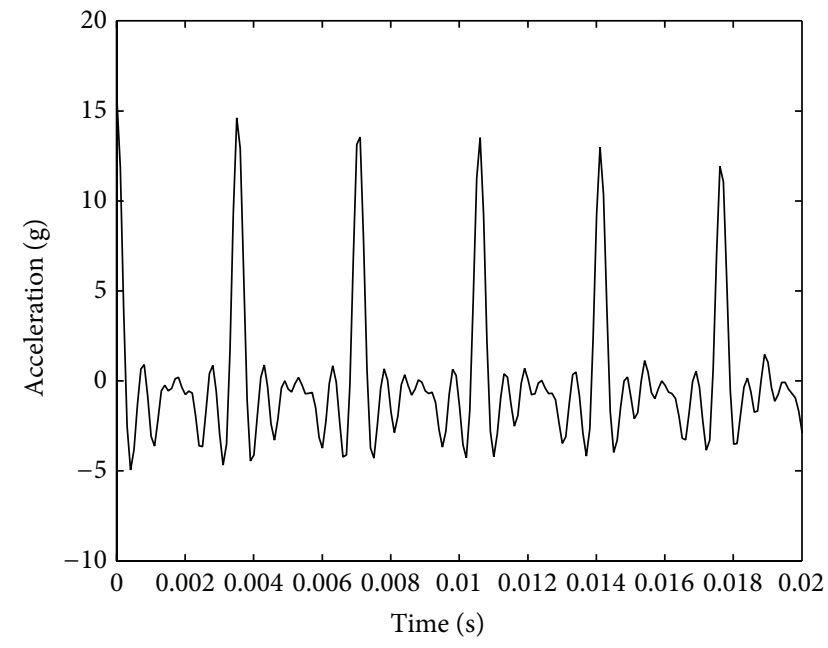

(b) The waveform after the noise reduction

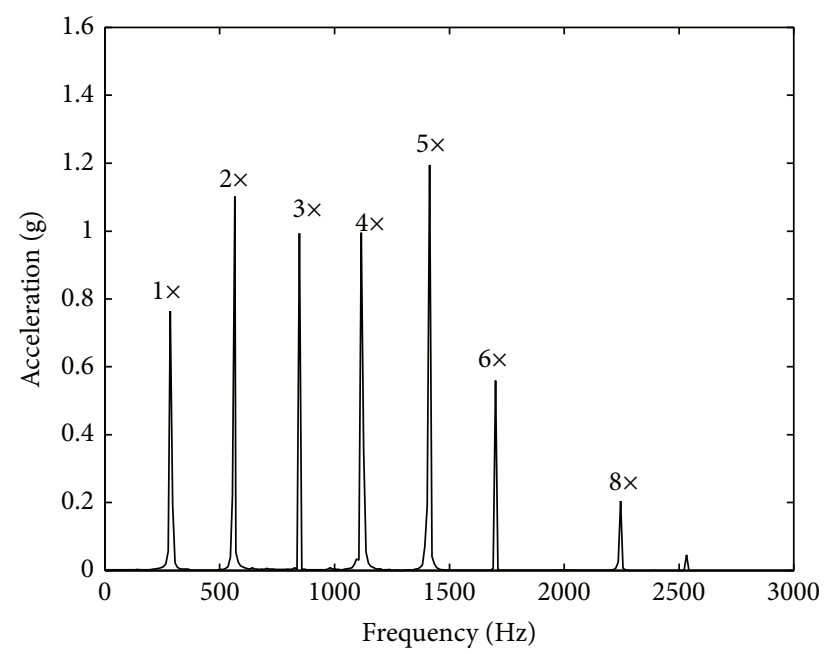

(d) The spectrum after the noise reduction

FIGURE 15: The time domain waveform and frequency spectrum before and after the noise reduction when rotating speed is $17000 \mathrm{rpm}$.

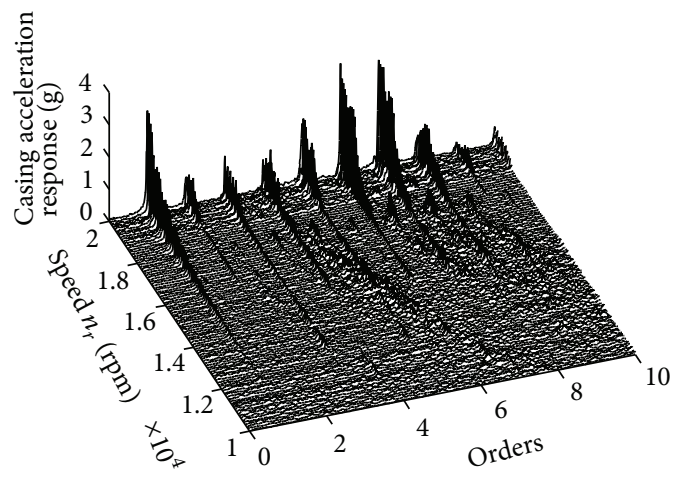

(a) Speeds from $10000 \mathrm{rpm}$ to $20000 \mathrm{rpm}$

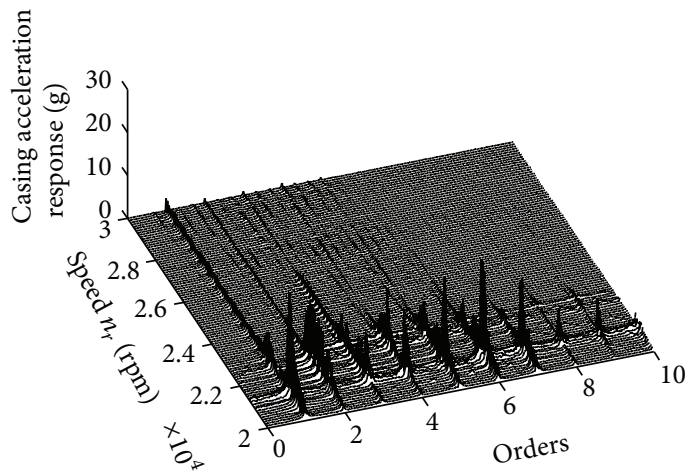

(b) Speeds from $20000 \mathrm{rpm}$ to $30000 \mathrm{rpm}$

FIGURE 16: Cascade plot of the casing acceleration response at different speeds. 


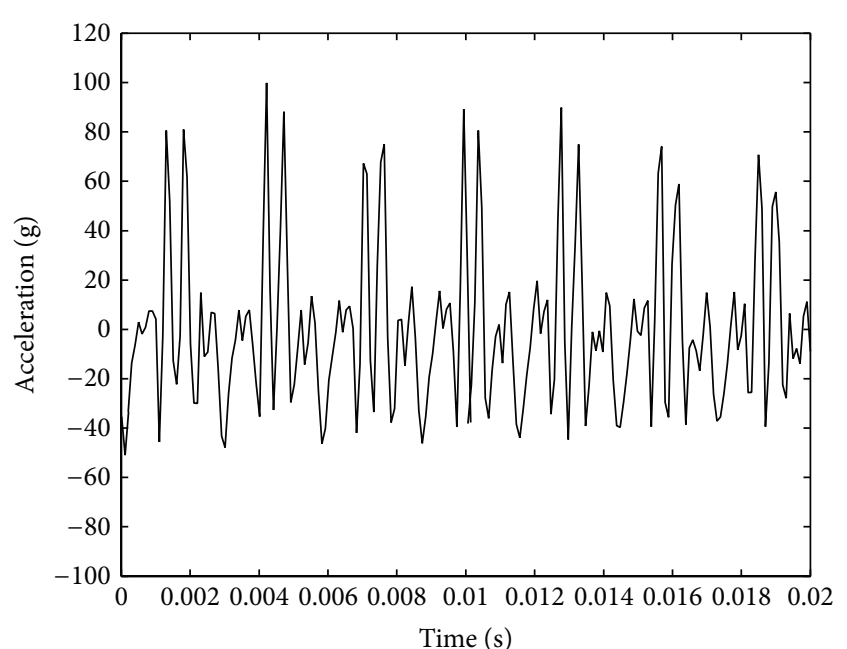

(a) The waveform before the noise reduction

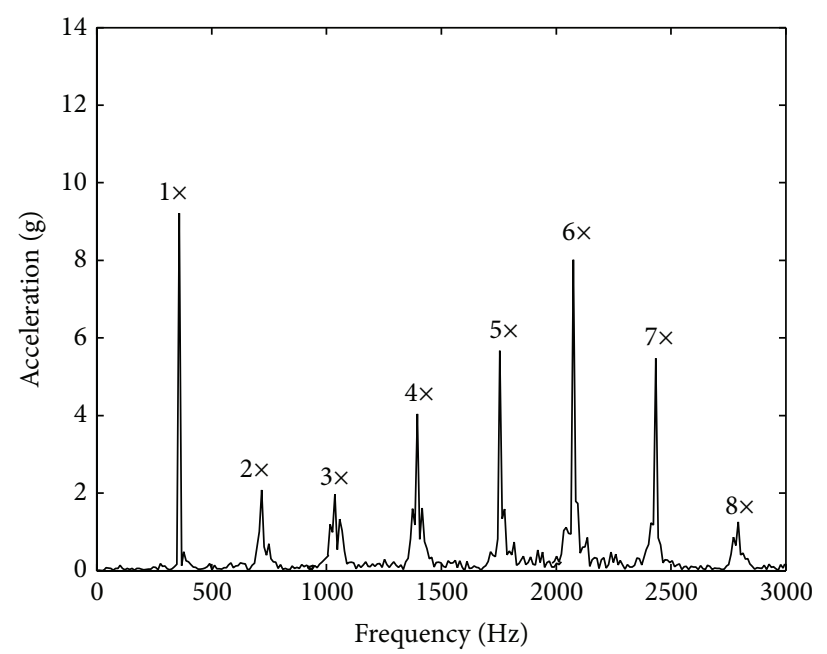

(c) The spectrum before the noise reduction

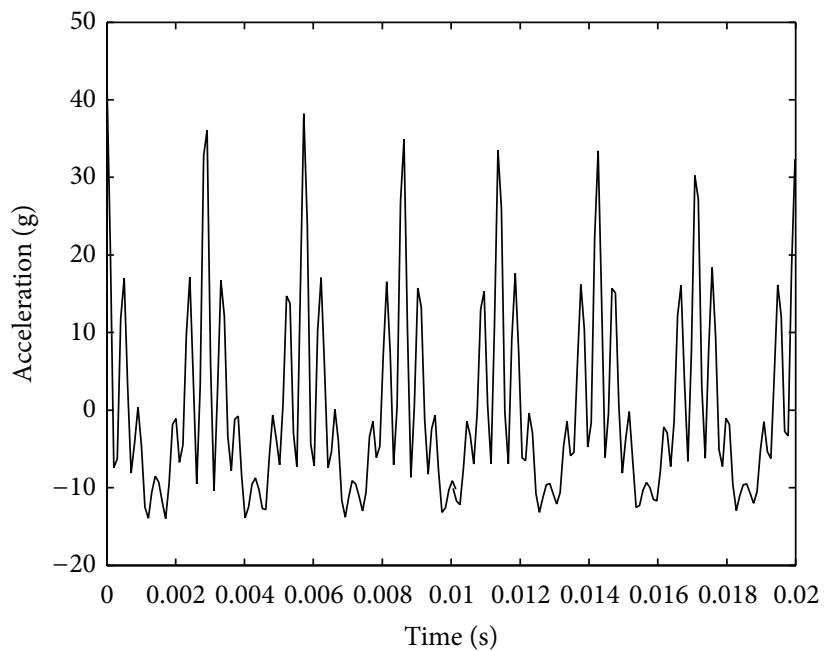

(b) The waveform after the noise reduction

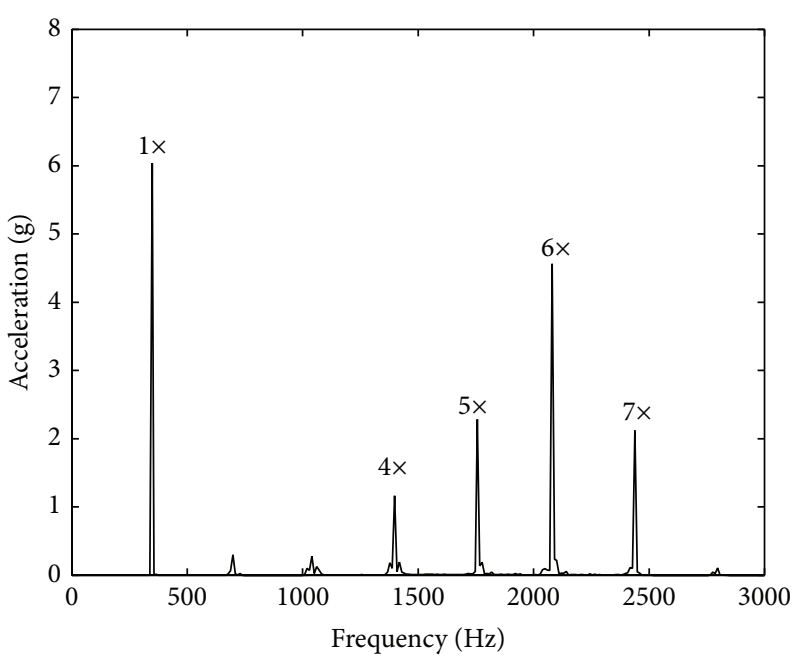

(d) The spectrum after the noise reduction

FIGURE 17: The time domain waveform and frequency spectrum before and after the noise reduction when rotating speed is $21000 \mathrm{rpm}$.

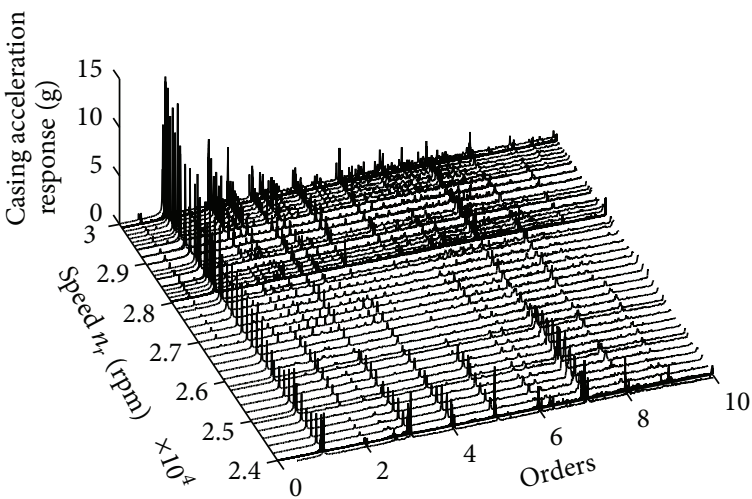

(a) Horizontal measuring point

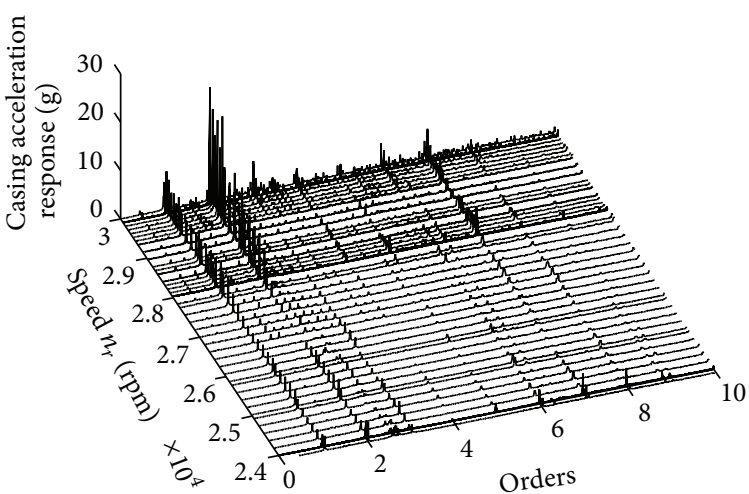

(b) Vertical measuring point

FIGURE 18: Cascade plot of casing acceleration response at different measuring points. 


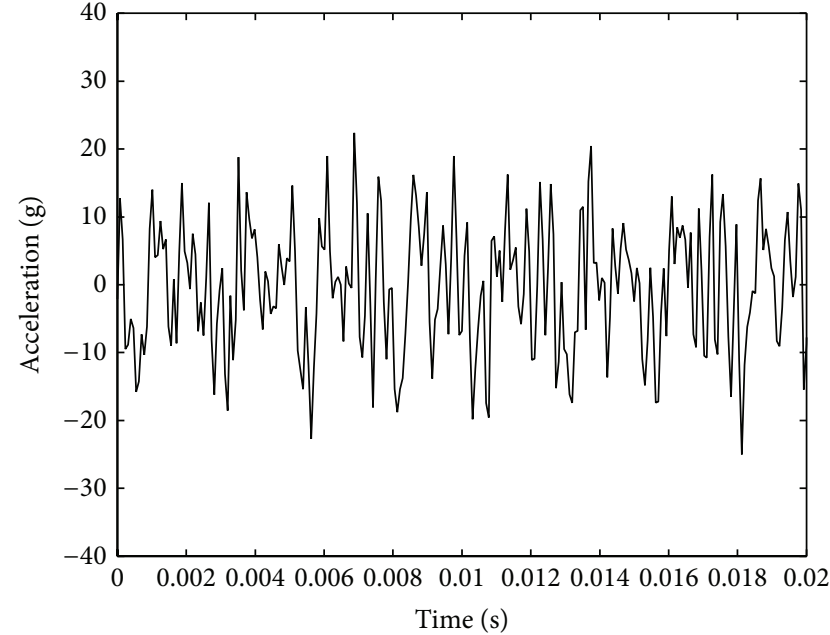

(a) The waveform before the noise reduction

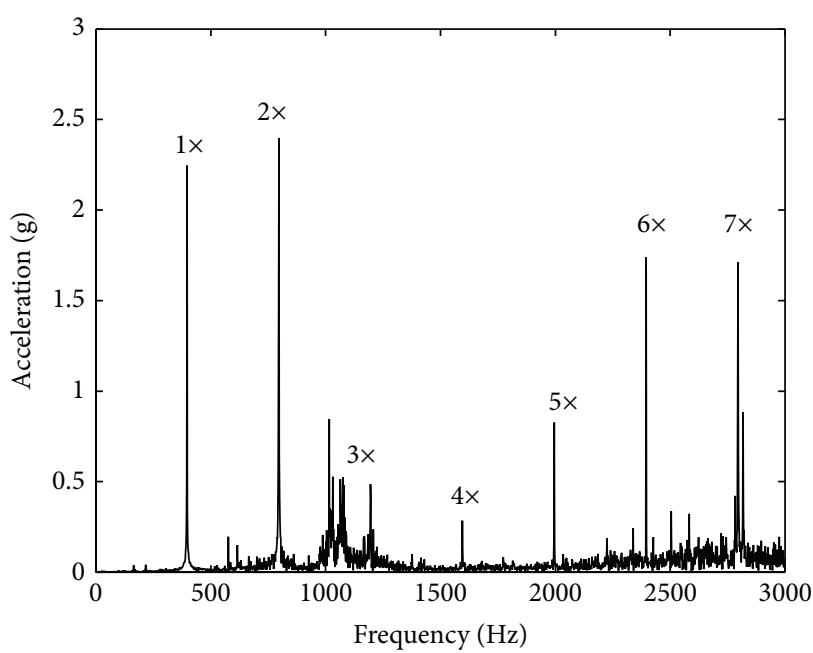

(c) The spectrum before the noise reduction

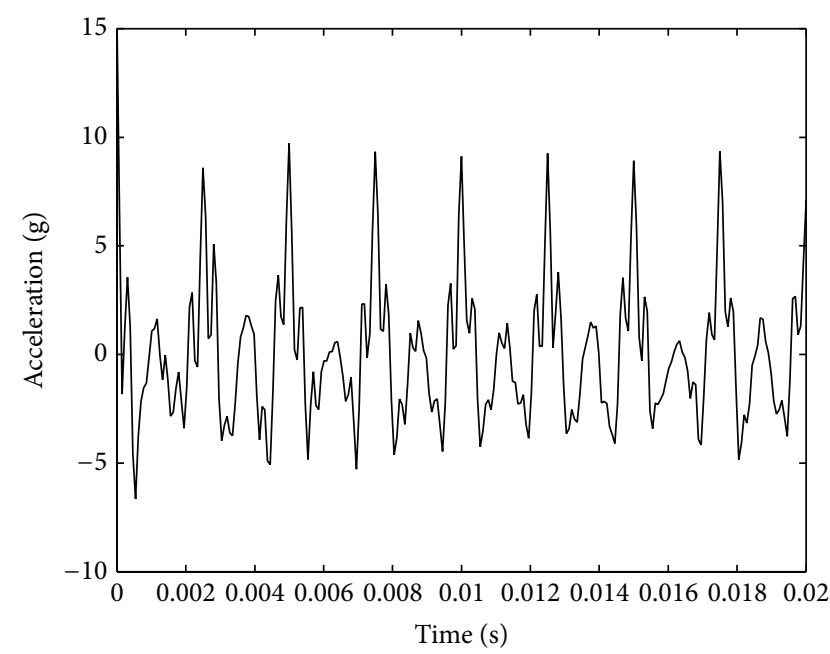

(b) The waveform after the noise reduction

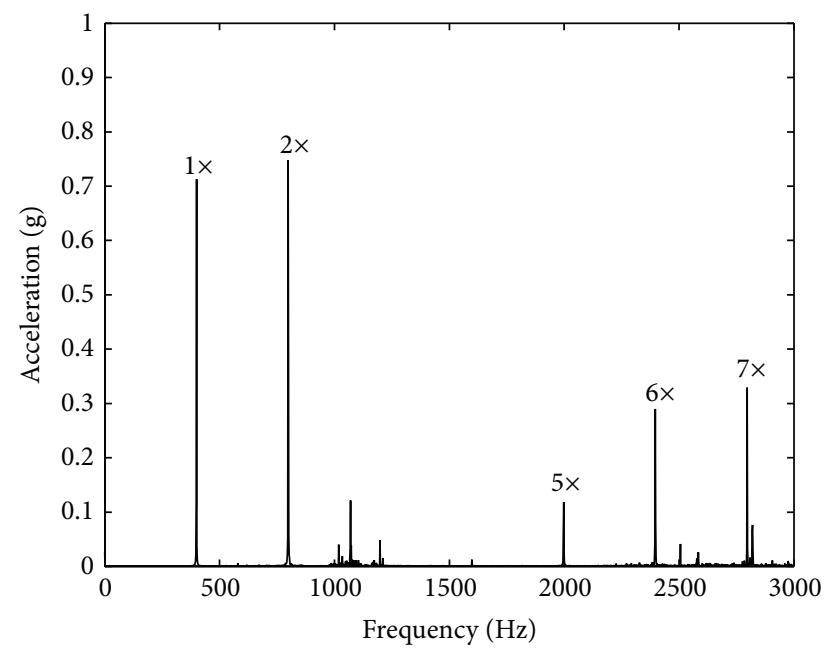

(d) The spectrum after the noise reduction

FIGURE 19: The time domain waveform and frequency spectrum before and after the noise reduction when rotating speed is $24000 \mathrm{rpm}$.

$27000 \mathrm{rpm}$, and $29000 \mathrm{rpm}$, respectively, which is obtained before and after the noise reduction of autocorrelation. As can be seen from the figures, the time domain waveform characteristics before the noise reduction of autocorrelation are not obvious; however, the waveforms after the noise reduction of autocorrelation have a typical shock characteristic with the waveform of truncated shape, which is longitudinal asymmetrical one. The real trial running data and the decomposition of the engine show that the turbofan engine presents the bearing outer ring obvious signs of wear and uneven wear phenomena, which proves the existence of support looseness. Based on more fault simulation analysis, only the asymmetric stiffness of the looseness fault excites the casing acceleration signal, which is very similar to the real trial running data. Not only are the multiple frequency characteristics similar in the frequency domain, but also the waveforms after the noise reduction of autocorrelation have a typical shock characteristic, with the waveform of truncated shape, which is longitudinal asymmetrical one. To some extent, the source of the engine fault is determined by the support looseness, which indicates that the looseness fault would be a main fault.

\section{Connector Looseness Fault Experimental Verification}

5.1. Connector Looseness Experiment Principle. In order to verify the nonsynchronous response characteristics of connector looseness fault, the experiment rig with looseness clearance is established, and the connector looseness experiment is carried out. Figure 22 is the experimental site map of looseness fault, Figure 23 is the experimental schematic diagram of looseness fault, and Figure 24 is the experimental three-dimensional diagram of looseness fault.

Figure 24 shows that the second disk is connected to the third disk by spring $k_{1}$, the third disk is connected to vibrating table by bolts, and the first disk is connected to the third disk by using three polish rods. Then the first disk, the third disk, 


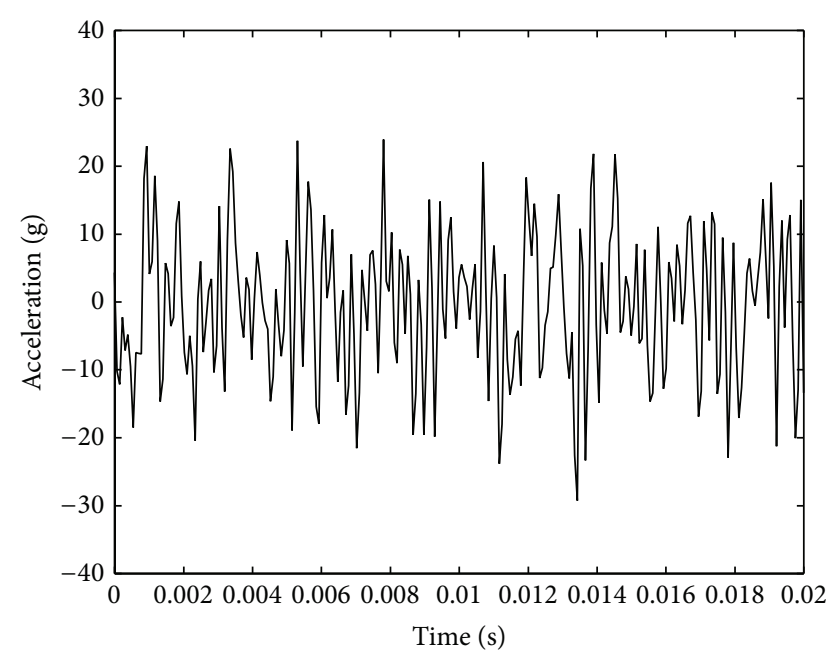

(a) The waveform before the noise reduction

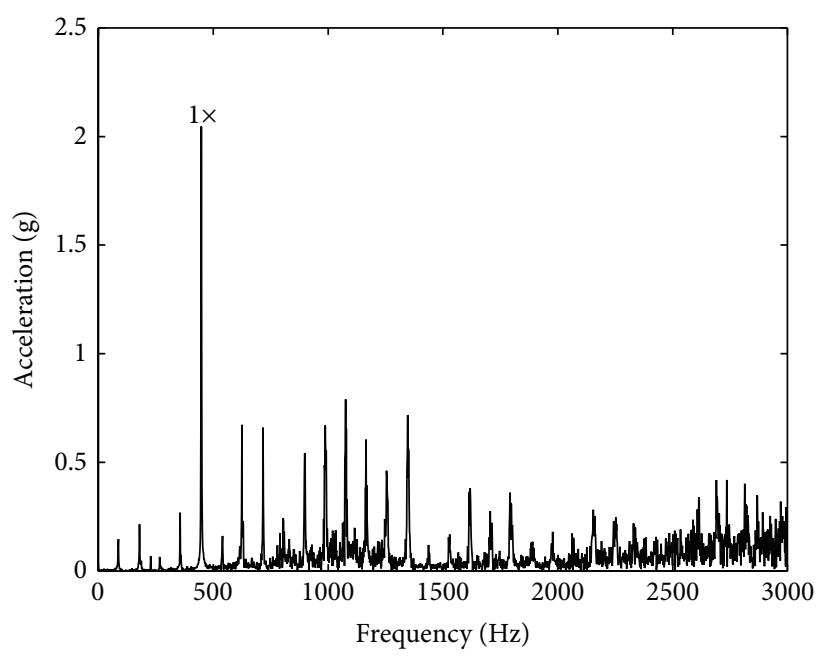

(c) The spectrum before the noise reduction

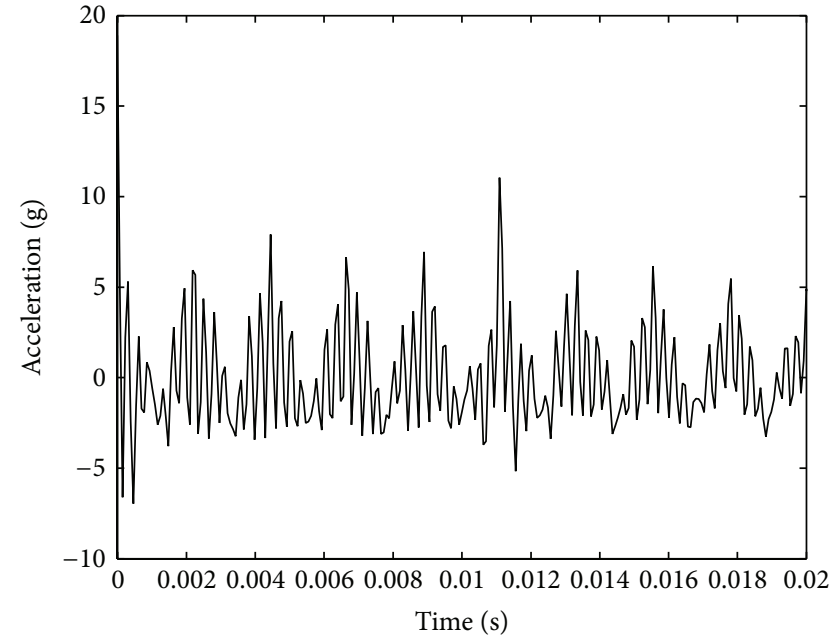

(b) The waveform after the noise reduction

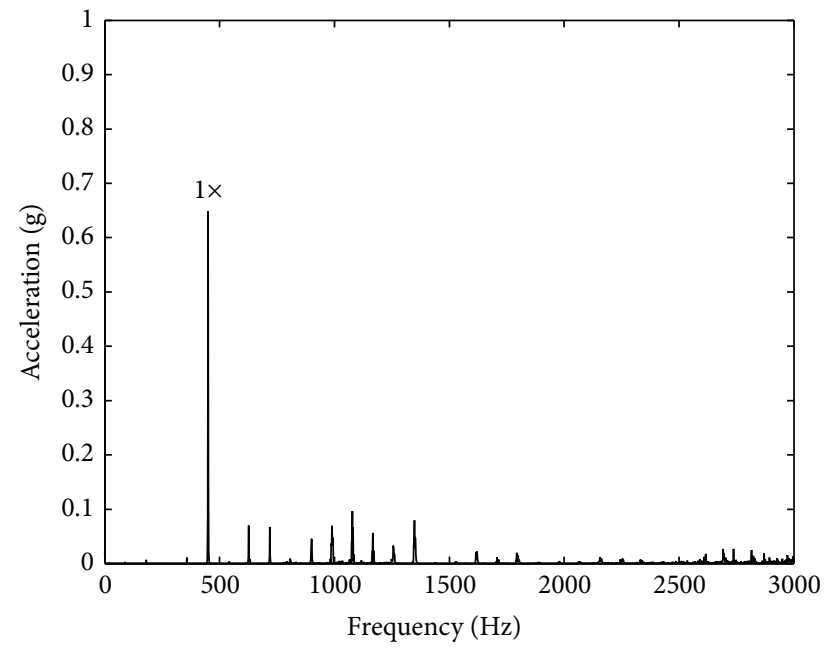

(d) The spectrum after the noise reduction

FIGURE 20: The time domain waveform and frequency spectrum before and after the noise reduction when rotating speed is $27000 \mathrm{rpm}$.

and vibrating table will vibrate together. The first disk and the second disk are connected by spring $k_{2}$, and the connector looseness fault is simulated by controlling the clearance.

During the experiment, the first disk, the third disk, and vibration table vibrate together, and the basement excitation to the second disk is carried out. When the relative displacement between the second disk and the third disk is smaller, the spring $k_{2}$ does not connect with the second disk, so the spring connection stiffness is only $k_{1}$. When the relative displacement between the second disk and the third disk is larger, the spring $k_{2}$ connects with the second disk, so the spring connection stiffness is $k_{1}+k_{2}$.

The energy of vibrating table is input by power amplifier and the feedback of vibration signals is realized by controlling the software and the vibration acceleration sensor on the third disk. The vibration of the vibrating table is controlled at the designated frequency and amplitude by vibration controller. The vibration acceleration of the second disk is measured by the vibration acceleration sensor on the second disk.
The collected digital signals are input into the computer for preservation by NI USB-9234 capture card.

In order to obtain the vibration performance of the vibration system, the excitation on vibrating table is applied by using the linear sine sweep frequency method from $5 \mathrm{~Hz}$ to $100 \mathrm{~Hz}$, and the looseness fault characteristics at different frequencies are obtained.

\subsection{Looseness Fault Experiment Verification}

5.2.1. Analysis of the Second Disk Response at Different Contact Forms. In the experiment, the acceleration of the second disk is measured by three methods; namely, (1) when the second disk does not contact with the spring $k_{2}$, the second disk only contacts with the third disk through spring $k_{1}$, the vibration system is a linear system, and the experiment result is shown in Figure 25(a); (2) when the second disk always contacts with the spring $k_{2}$, the second disk contacts with the third disk and the first disk through spring $k_{1}$ and $k_{2}$, the vibration system is 


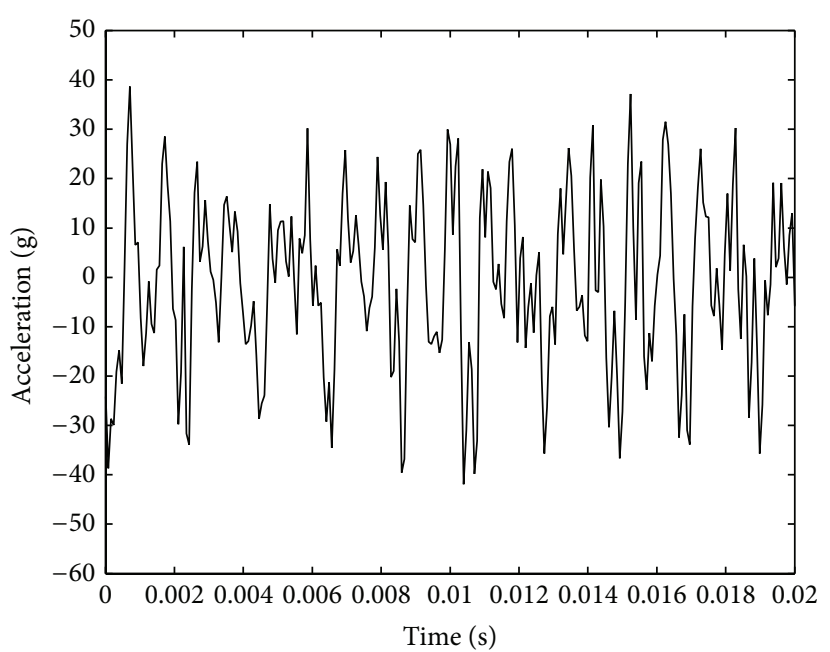

(a) The waveform before the noise reduction

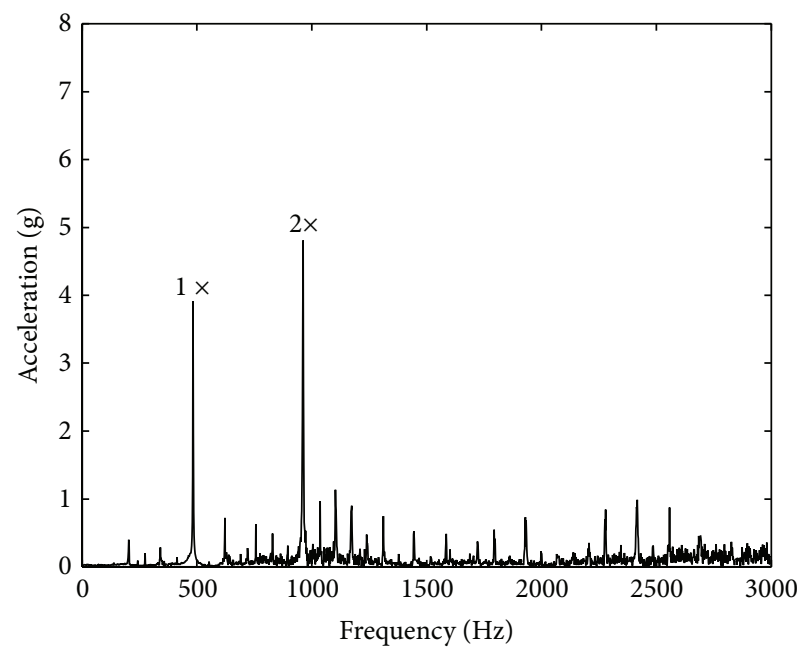

(c) The spectrum before the noise reduction

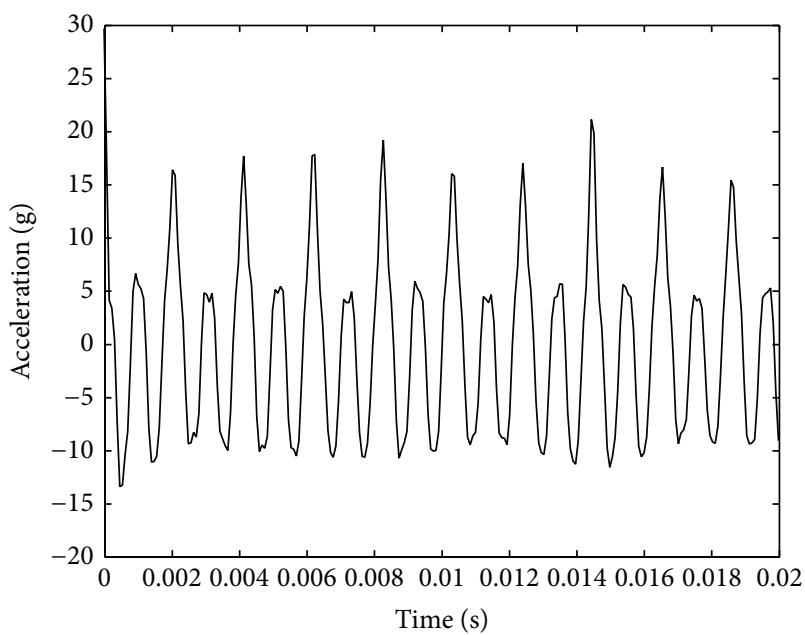

(b) The waveform after the noise reduction

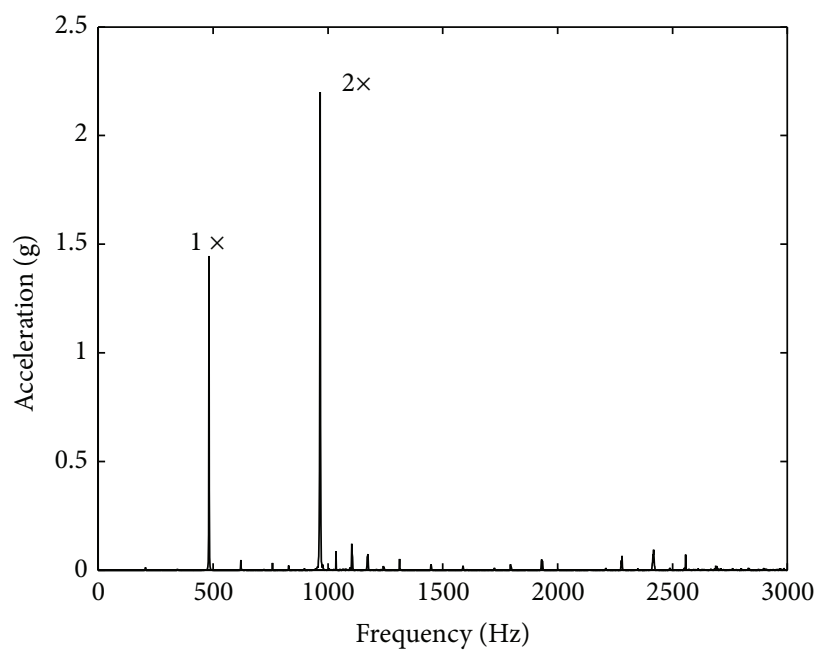

(d) The spectrum after the noise reduction

FIGURE 21: The time domain waveform and frequency spectrum before and after the noise reduction when the rotating speed is $29000 \mathrm{rpm}$.

also a linear system, its spring connection stiffness is $k_{1}+k_{2}$, and the experiment result is shown in Figure 25(b); (3) when there is clearance between the second disk and spring $k_{1}$, at different relative vibration displacement between the second disk and the first disk, the second disk may contact with spring $k_{1}$ ornot, the vibration system is a nonlinear system, and the experiment result is shown in Figure 25(c).

Figure 25(a) shows that when the second disk does not contact with the spring $k_{2}$, the vibration system is a linear system, and its natural frequency is $14.6 \mathrm{~Hz}$. Figure 25(b) shows that when the second disk always contacts with the spring $k_{2}$, the vibration system is also a linear system, and its spring connection stiffness is $k_{1}+k_{2}$, so its natural frequency is $51.22 \mathrm{~Hz}$. When there is looseness clearance, the second disk may contact with spring $k_{1}$ or not. When the vibration displacement is large, the second disk will contact spring $k_{2}$ only half period in a movement period. At this time, the natural frequency of the system is [18]

$$
\frac{1}{f_{n}}=\frac{1}{2}\left(\frac{1}{f_{1}}\right)+\frac{1}{2}\left(\frac{1}{f_{2}}\right)
$$

According to (14), the calculated result $f_{n}$ is $22.7 \mathrm{~Hz}$, and the experimental result is $22.2 \mathrm{~Hz}$, shown in Figure 25(c). Obviously, the analysis results are verified fully.

5.2.2. Analysis of Looseness Characteristics. Figure 26 is three-dimensional cascade plot of the second disk vibration acceleration changing with excitation frequency and response frequency. Figure 26 shows that the frequency multiplication appears when excitation frequency is $1 / 2 f_{n}, 1 / 2$ frequency division appears when excitation frequency is $2 f_{n}$, and $1 / 3$ frequency division appears when excitation frequency is $3 f_{n}$. 


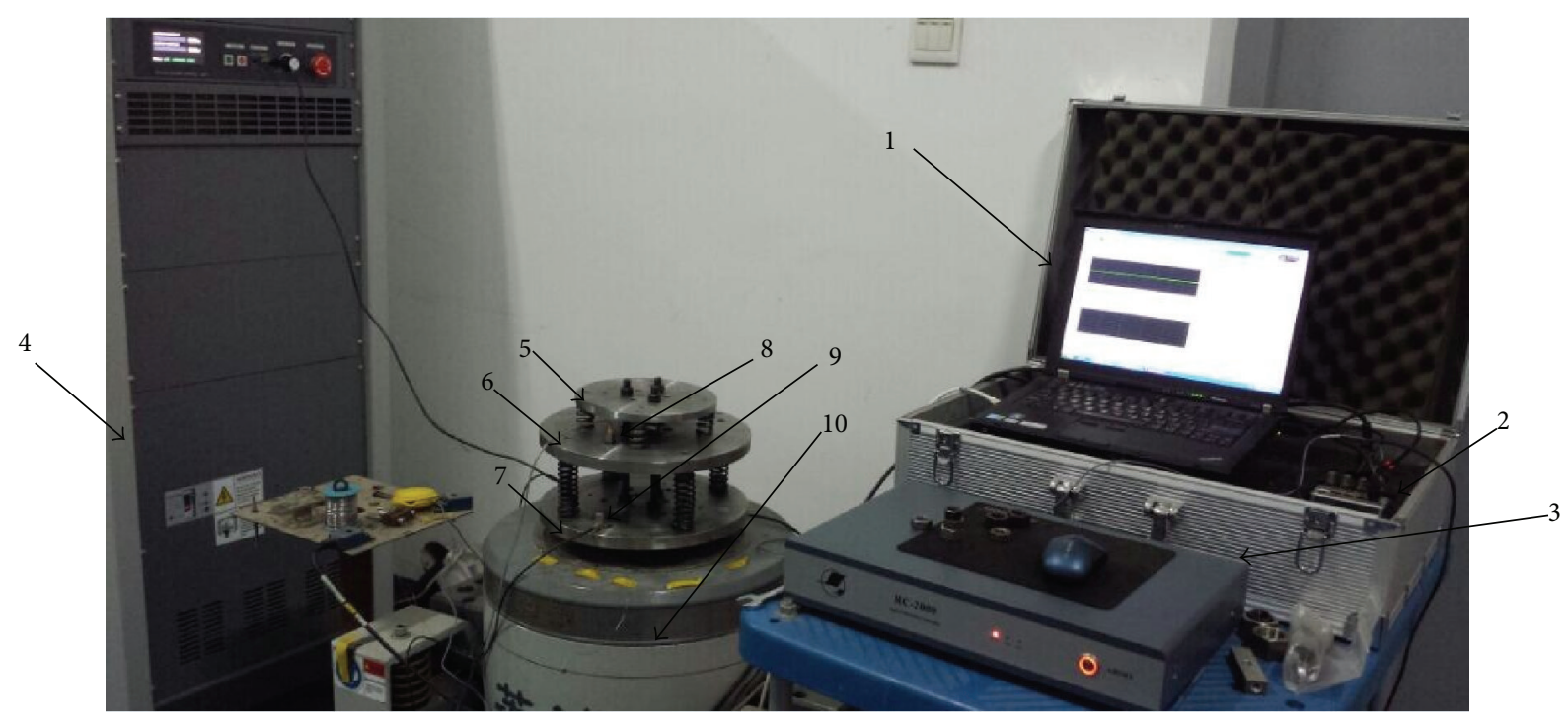

(1) Computer

(2) NI USB-9234 data acquisition card

(3) Vibration controller

(4) Power amplifier

(5) The first disk
(6) The second disk

(7) The third disk

(8) Acceleration sensor (B\&k4508)

(9) Acceleration sensor for controller

(10) Vibrating table

FIGURE 22: The experimental site map of looseness fault.

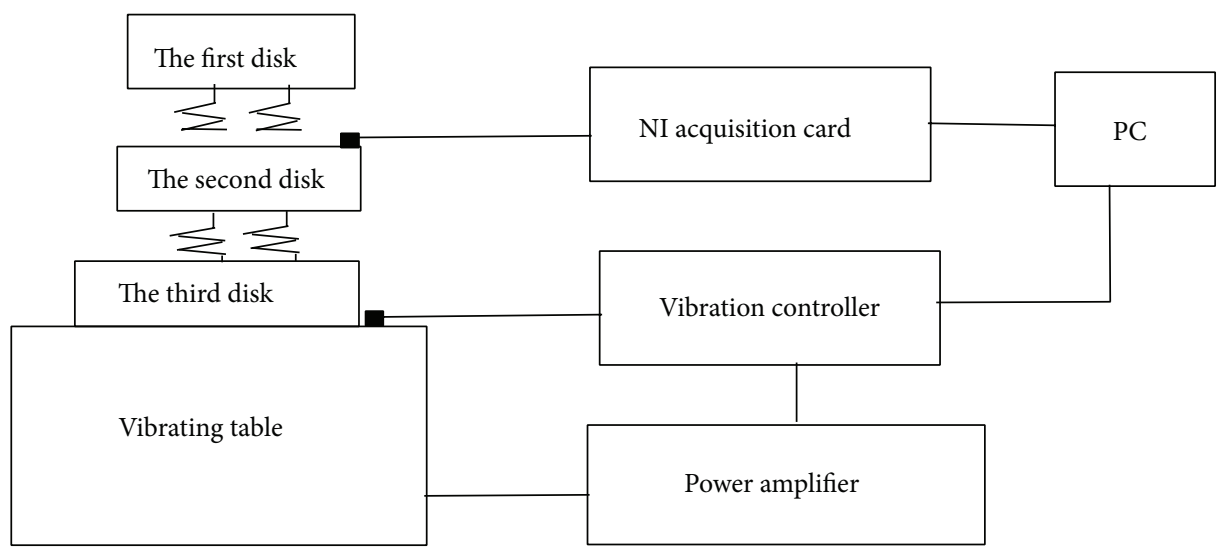

FIGURE 23: Experimental schematic diagram of looseness fault.

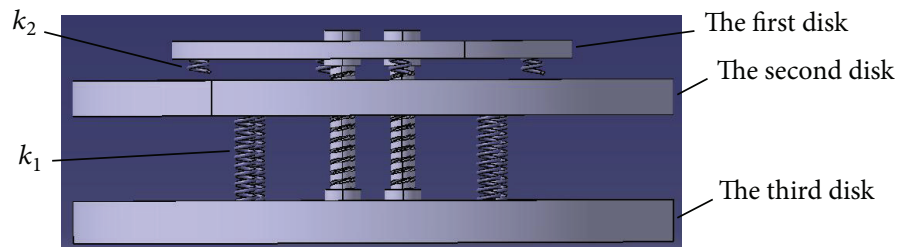

FIgURE 24: Experimental three-dimensional diagram of looseness fault. 


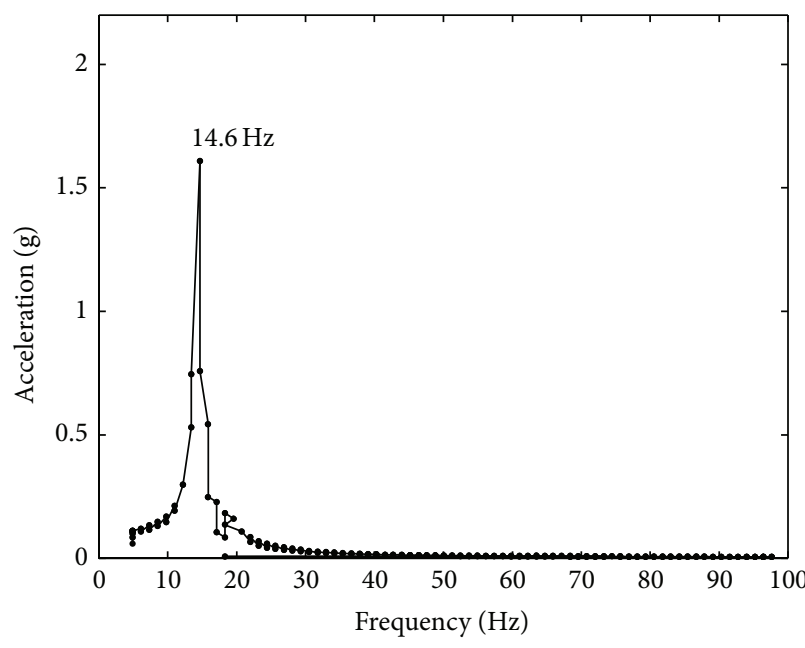

(a) No contact between the second disk and spring $k_{2}$

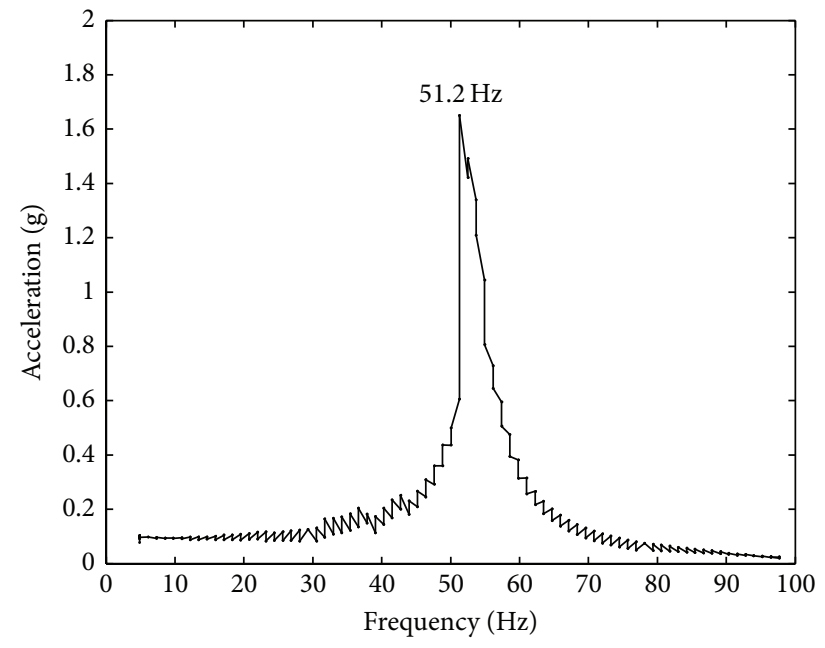

(b) Complete contact between the second disk and spring $k_{2}$

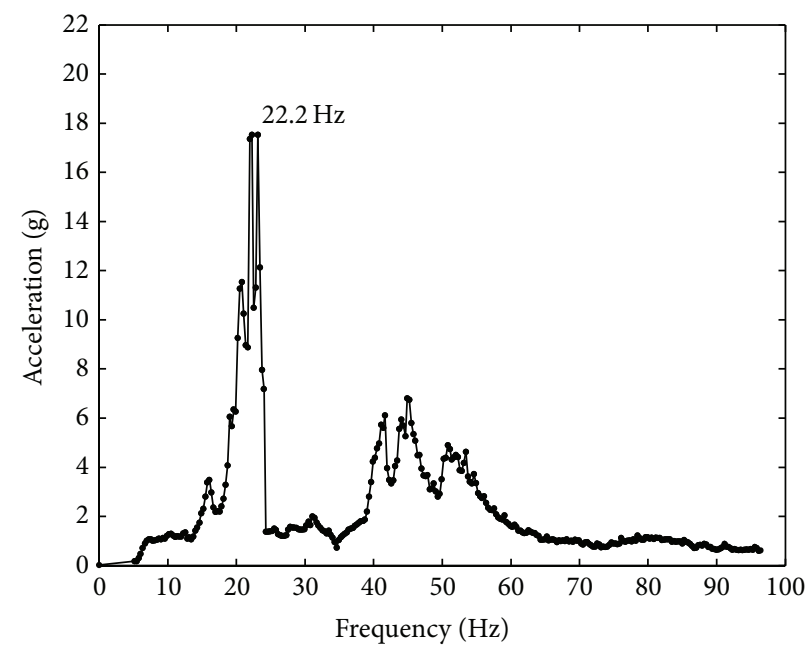

(c) Discontinuous contact between the second disk and spring $k_{2}$

FIGURE 25: The response of the second disk under different contact conditions.

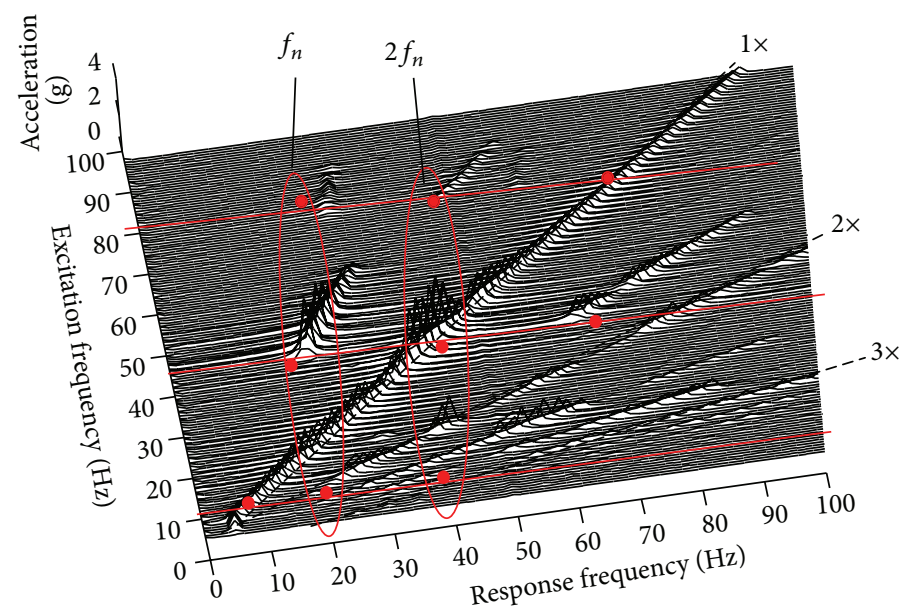

Figure 26: Cascade plot of the second disk response. 


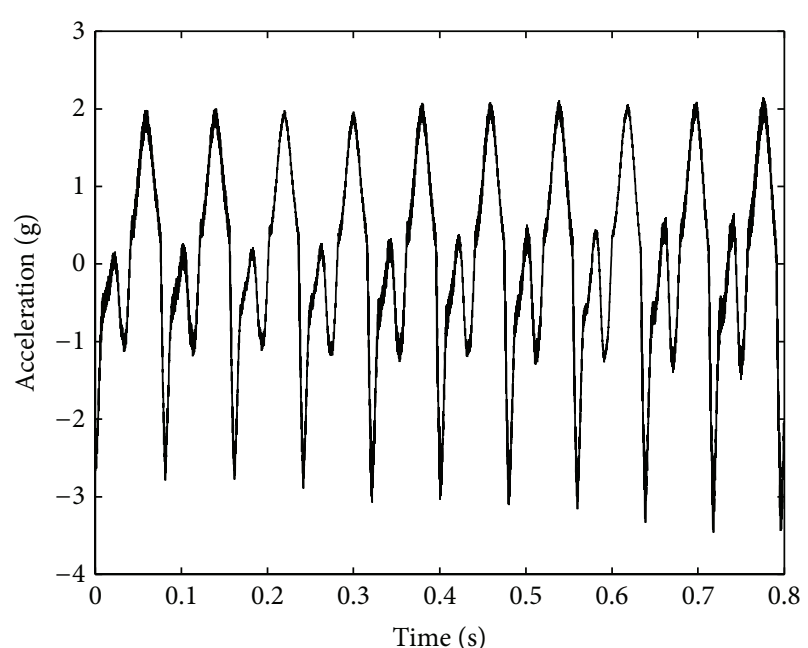

(a) The waveform before the noise reduction

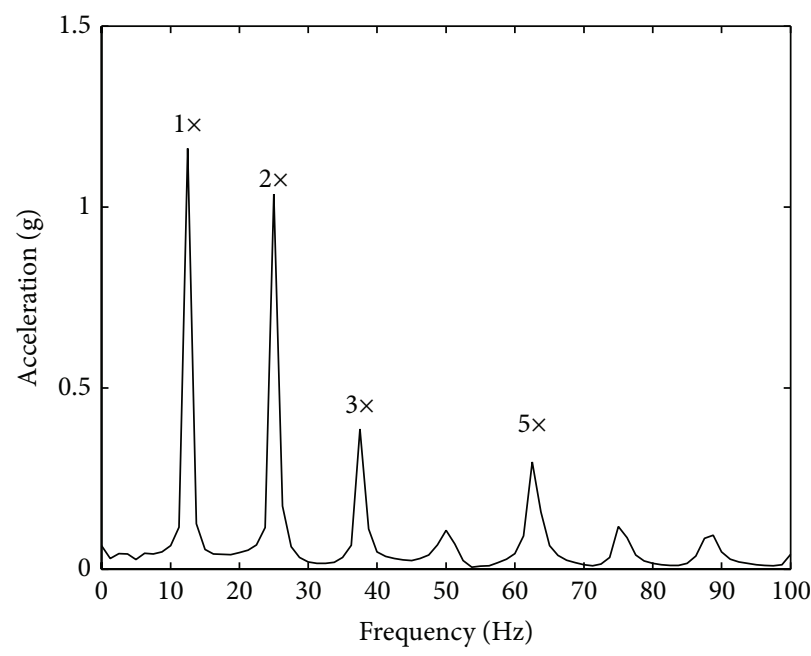

(c) The spectrum before the noise reduction

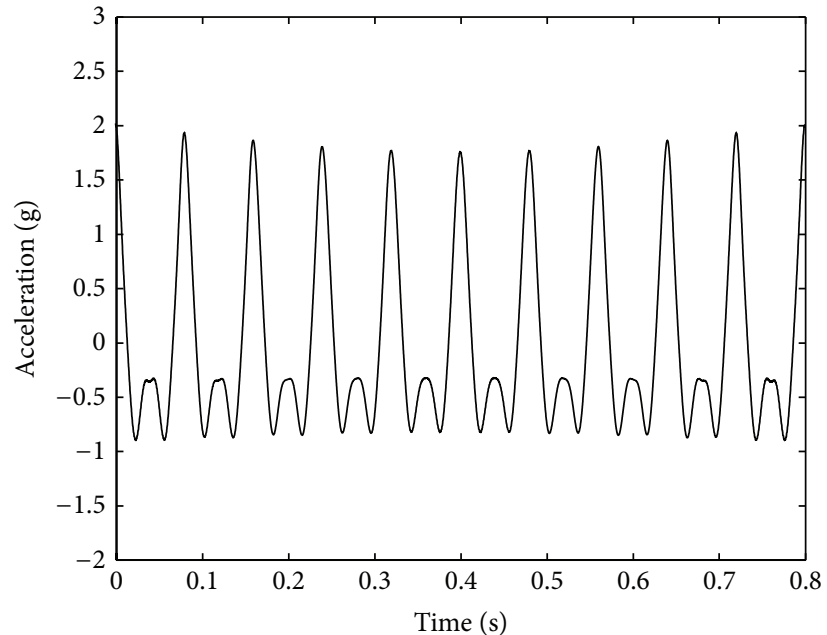

(b) The waveform after the noise reduction

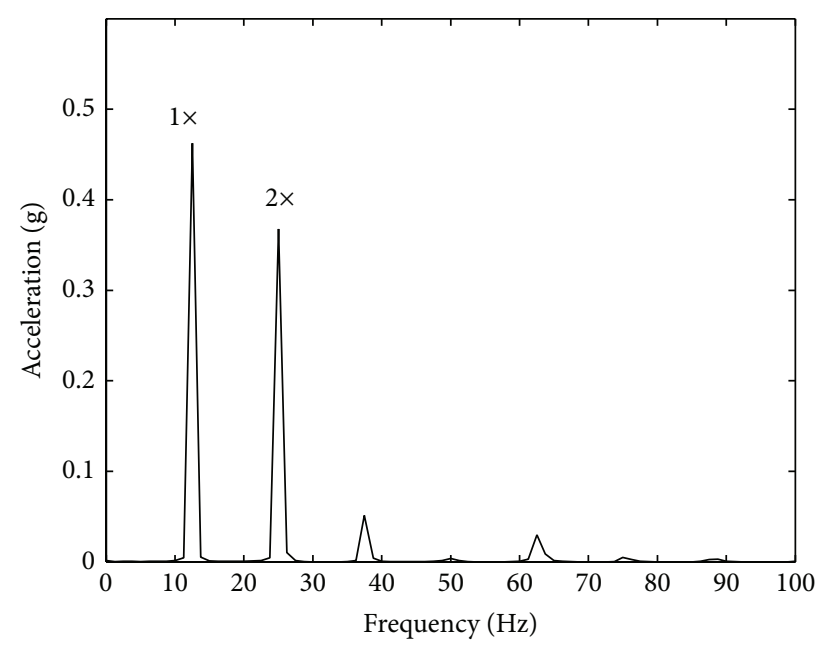

(d) The spectrum after the noise reduction

FIGURE 27: Waveform and frequency spectrum before and after the noise reduction when frequency is $1 / 2 f_{n}$.

Figure 27 shows time domain waveform and spectrum of the second disk when the excitation frequency is $12.5 \mathrm{~Hz}$, which is obtained before and after the noise reduction of autocorrelation. As shown in Figure 27, when the excitation frequency is equal to $1 / 2 f_{n}$, the larger double frequency components appeared, that is, the natural frequency of the system; the waveforms after the noise reduction of autocorrelation have a typical shock characteristic with the waveform of truncated shape, which is longitudinal asymmetrical one.

Figure 28 shows time domain waveform and spectrum of the second disk when the excitation frequency is $45 \mathrm{~Hz}$, which is obtained before and after the noise reduction of autocorrelation. As shown in Figure 28, when the frequency of the vibration table is equal to $2 f_{n}$, the larger $1 / 2$ dividing frequency components appeared, that is, the natural frequency of the system; the waveforms after the noise reduction of autocorrelation have a typical shock characteristic with the waveform of truncated shape, which is longitudinal asymmetrical one.

Figure 29 shows time domain waveform and spectrum of the second disk when the excitation frequency is $80 \mathrm{~Hz}$, which is obtained before and after the noise reduction of autocorrelation. As shown in Figure 29, when the frequency of the vibrating table is about $3 f_{n}$, the larger $1 / 3$ dividing frequency components appeared, that is, the natural frequency of the system; the waveforms after the noise reduction of autocorrelation have a typical shock characteristic, with the waveform of truncated shape, which is longitudinal asymmetrical one.

By comparison, in different frequencies of the vibrating table, for connector looseness fault, the acceleration waveforms after the noise reduction of autocorrelation have the characteristic that is a typical shock characteristic, with the waveform of truncated shape, which is longitudinal 


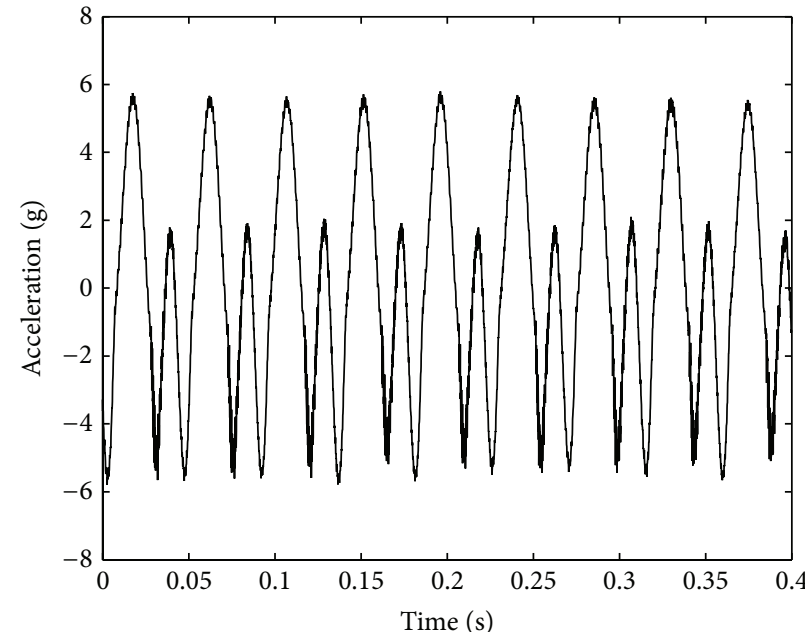

(a) The waveform before the noise reduction

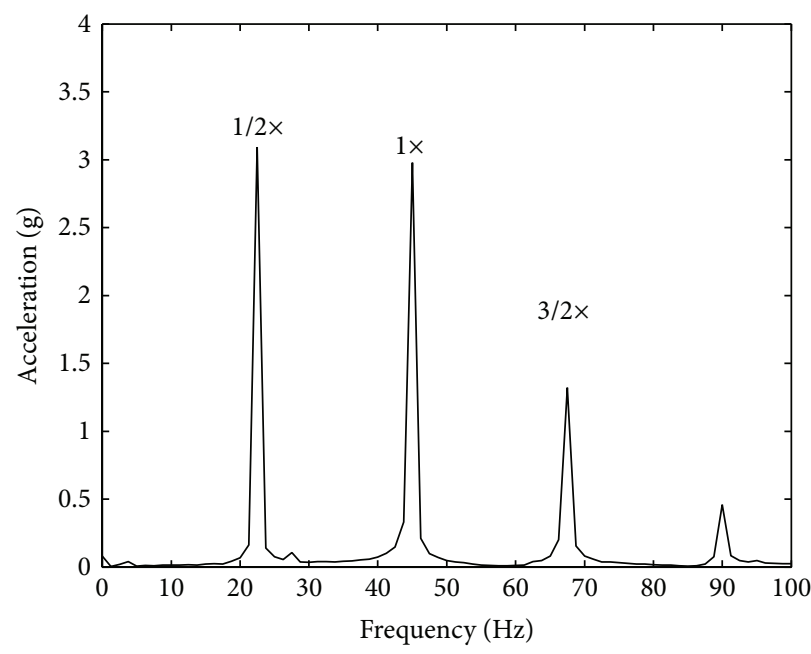

(c) The spectrum before the noise reduction

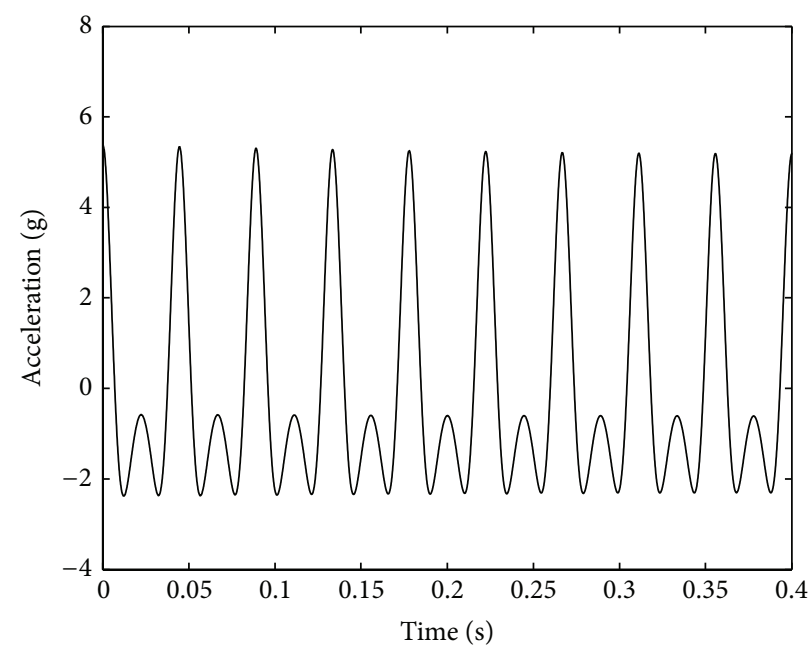

(b) The waveform after the noise reduction

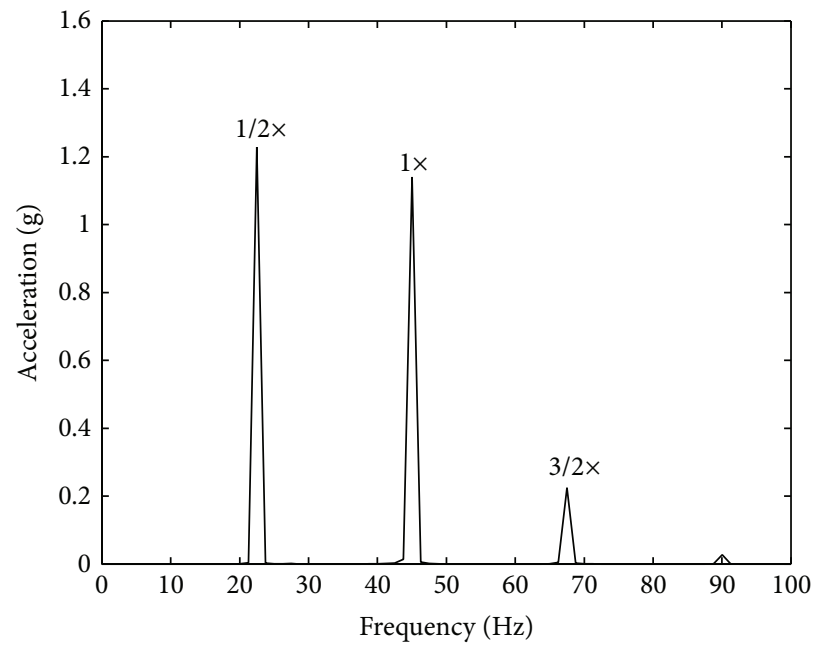

(d) The spectrum after the noise reduction

FIGURE 28: Waveform and frequency spectrum before and after the noise reduction when frequency is $2 f_{n}$.

asymmetrical one, which could be identified as the waveforms after the noise reduction of autocorrelation have a typical shock characteristic, of the looseness fault.

\section{Conclusion}

In this paper, certain type turbofan engine whole vibration model with support looseness fault is established and casing acceleration response is obtained. Some results are obtained as follows.

(1) Aiming at certain type turbofan engine, the dynamic model with the looseness fault is established. The nonlinear rolling bearing is considered in the model. A variety of support connections are used, that is, the support connection between the casing and the rotor; the coupling connection between two rotors; and the elastic connection between the rotor and the casing.
(2) The looseness models of asymmetric stiffness and symmetric stiffness are established. The looseness fault exists between the bearing and the casing. Numerical simulation method is used to obtain the engine casing acceleration response under the looseness fault.

(3) The simulation results are compared with the real trial running vibration signals and connector looseness fault experiment, and the simulated fault characteristics are very similar with the real trial running vibration characteristics and the connectors looseness characteristics. The waveforms have the characteristic that is a typical shock characteristic, with the waveform of truncated shape, which is longitudinal asymmetrical one, and there are many multiple frequency components and dividing frequency components, which could provide a qualitative judgment of the support looseness fault for the engine fault diagnosis. 


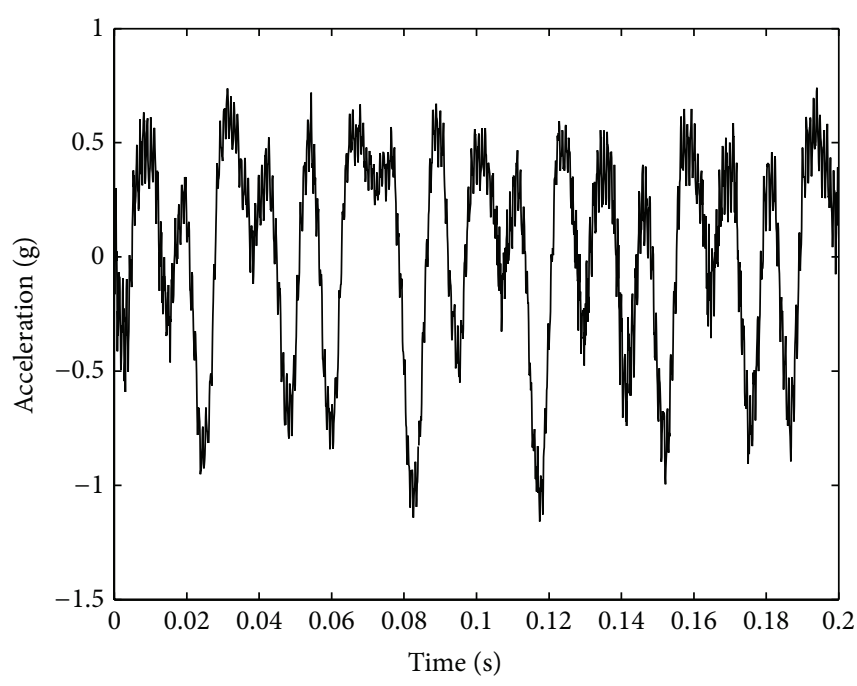

(a) The waveform before the noise reduction

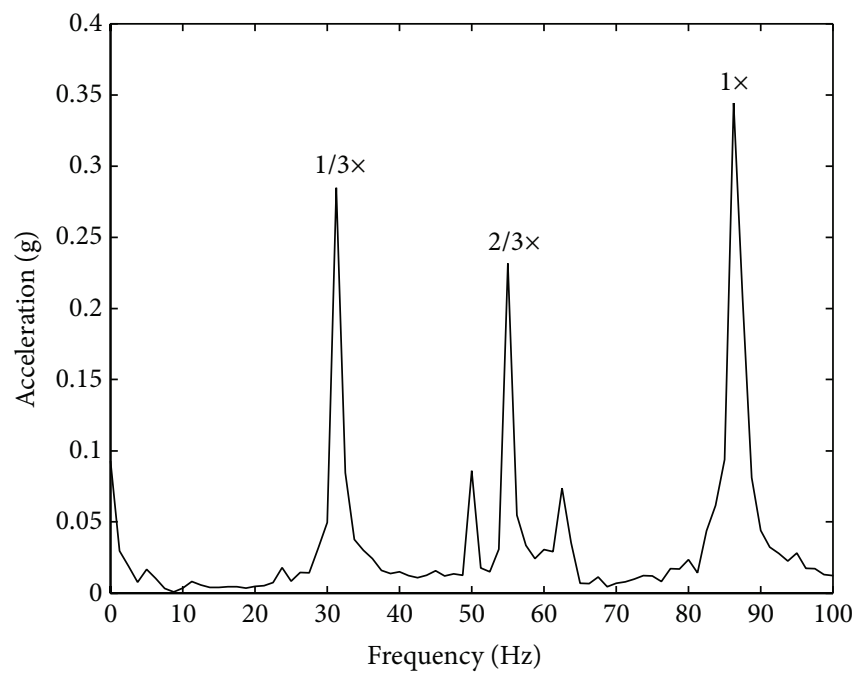

(c) The spectrum before the noise reduction

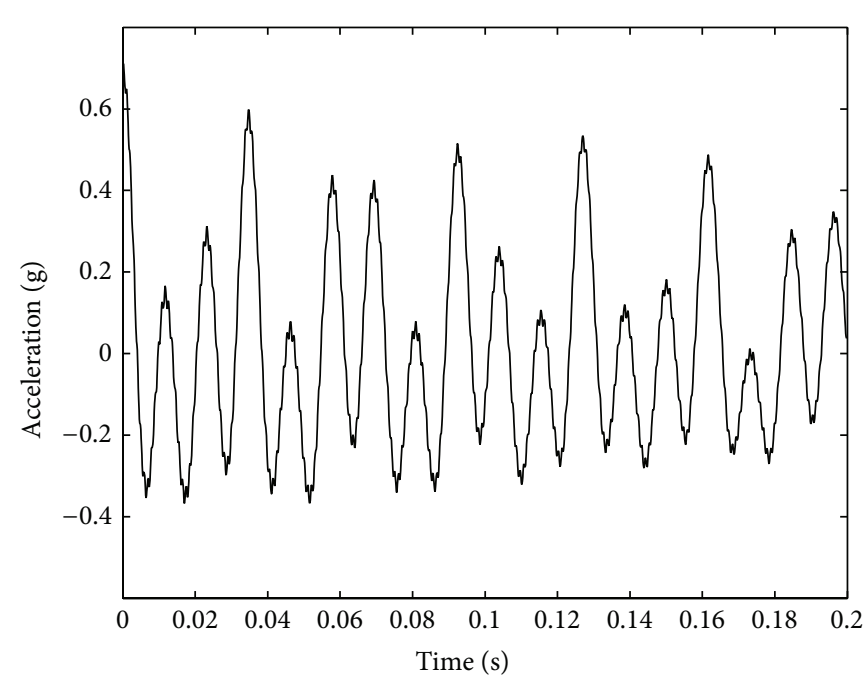

(b) The waveform after the noise reduction

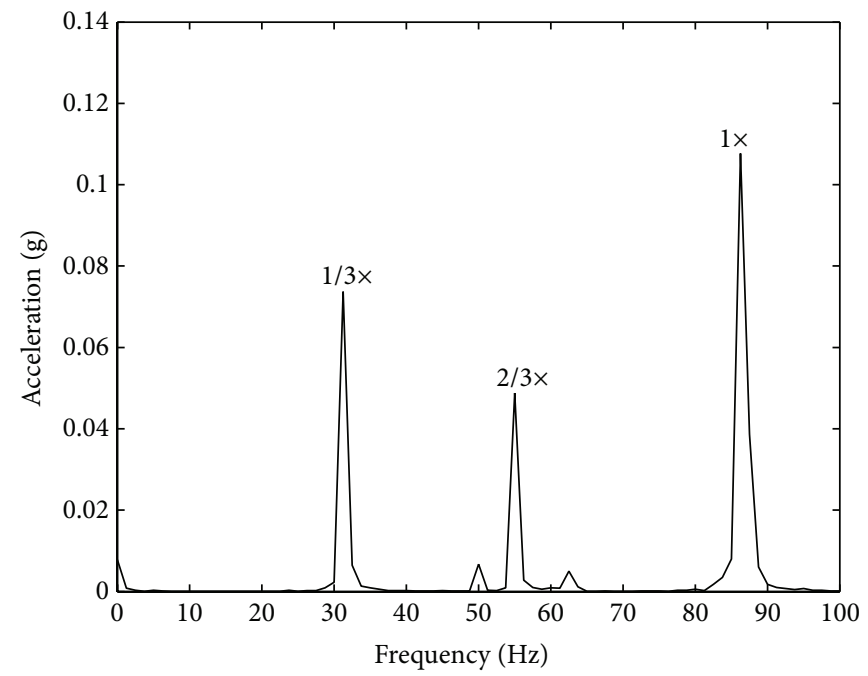

(d) The spectrum after the noise reduction

FIGURE 29: Waveform and frequency spectrum before and after the noise reduction when frequency is $3 f_{n}$.

In addition, the comparison results of the simulation and the real trial running vibration signals also show the validity of the asymmetric stiffness looseness model.

\section{Conflict of Interests}

The authors declare that there is no conflict of interests regarding the publication of this paper.

\section{Acknowledgments}

This work is supported by funding of Jiangsu Innovation Program for Graduate Education (KYLX_0295), the Fundamental Research Funds for the Central Universities, and the NUAA Fundamental Research Funds (no. NS2013070).

\section{References}

[1] A. Muszynska and P. Goldman, "Chaotic responses of unbalanced rotor/bearing/stator systems with looseness or rubs," Chaos, Solitons \& Fractals, vol. 5, no. 9, pp. 1683-1704, 1995.

[2] P. Goldman and A. Muszynska, "Smoothing technique for rub or looseness-related rotor dynamic problem," in Proceedings of the 15th ASME Biennial Vibration and Noise Conference, pp. 565-572, September 1995.

[3] A. Muszynska, "Effects of loose rotating parts on rotor dynamics," in Proceedings of the 4th International Conference on Vibrations in Rotating Machinery, pp. 573-578, 1988.

[4] F. Chu and Y. Tang, "Stability and non-linear responses of a rotor-bearing system with pedestal looseness," Journal of Sound and Vibration, vol. 241, no. 5, pp. 879-893, 2001.

[5] G. Chen, "Nonlinear dynamics of unbalance-looseness coupling faults of rotor-ball bearing-stator coupling system," Chinese Journal of Mechanical Engineering, vol. 44, no. 3, pp. 82-88, 2008 (Chinese). 
[6] W. Lu and F. Chu, "Experimental investigation of pedestal looseness in a rotor-bearing system," Key Engineering Materials, vol. 413-414, pp. 599-605, 2009.

[7] Z. Ji and J. W. Zu, "Method of multiple scales for vibration analysis of rotor-shaft systems with non-linear bearing pedestal model," Journal of Sound and Vibration, vol. 218, no. 2, pp. 293305, 1998.

[8] Y. He, Z. Chen, D. Guo, and F. Chu, "A genetic algorithm based inverse problem approach for pedestal looseness identification in rotor-bearing systems," Key Engineering Materials, vol. 245246, pp. 115-122, 2003.

[9] S.-M. Lee and Y.-S. Choi, "Fault diagnosis of partial rub and looseness in rotating machinery using Hilbert-Huang transform," Journal of Mechanical Science and Technology, vol. 22, no. 11, pp. 2151-2162, 2008.

[10] M. C. S. Reddy and A. S. Sekhar, "Application of artificial neural networks for identification of unbalance and looseness in rotor bearing system," International Journal of Applied Science and Engineering, vol. 11, no. 1, pp. 69-84, 2013.

[11] H. Ma, Z. H. Ren, H. L. Yao et al., "Numerical simulation and experimental research on pedestal looseness of a rotor system," in ASME International Design Engineering Technical Conferences, 2007.

[12] M. Behzad and M. Asayeshthe, "Numerical and experimental investigation on vibration of rotors with loose disks," Proceedings of the Institution of Mechanical Engineers, Part C: Journal of Mechanical Engineering Science, vol. 223, pp. 1-10, 2010.

[13] A. S. Lee, B. O. Kim, and Y.-C. Kim, "A finite element transient response analysis method of a rotor-bearing system to base shock excitations using the state-space Newmark scheme and comparisons with experiments," Journal of Sound and Vibration, vol. 297, no. 3-5, pp. 595-615, 2006.

[14] H. Ma, X. Zhao, Y. Teng, and B. Wen, "Analysis of dynamic characteristics for a rotor system with pedestal looseness," Shock \& Vibration, vol. 18, no. 1-2, pp. 13-27, 2011.

[15] Editorial Board of Aero-Engine Design Manual, Aero-Engine Design Manual (19th Part): Rotor Dynamics and Whole Machine Vibration, Aerospace Industry Press, Beijing, China, 2000, (Chinese).

[16] G. Chen, C. G. Li, and D. Y. Wang, "Nonlinear dynamic analysis and experiment verification of rotor-ball bearings-supportstator coupling system for aeroengine with rubbing coupling faults," Journal of Engineering for Gas Turbines and Power, vol. 132, no. 2, Article ID 022501, 2010.

[17] W.-M. Zhai, "Two simple fast integration methods for largescale dynamic problems in engineering," International Journal for Numerical Methods in Engineering, vol. 39, no. 24, pp. 41994214, 1996.

[18] F. F. Ehrich, "A new class of asynchronous rotordynamic response in high-speed rotors," in Proceedings of the ASME Design Engineering Technical Conferences \& Computers and Information in Engineering Conference, pp. 1783-1788, Las Vegas, Nev, USA, September 2007. 

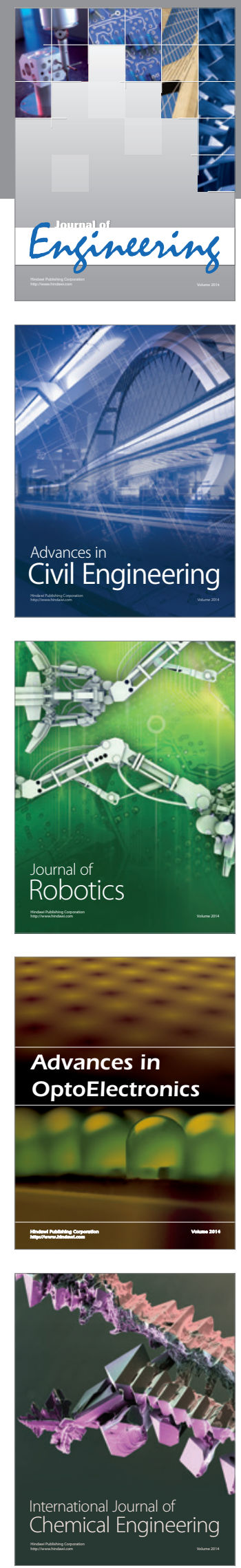

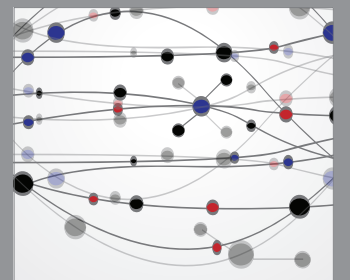

The Scientific World Journal
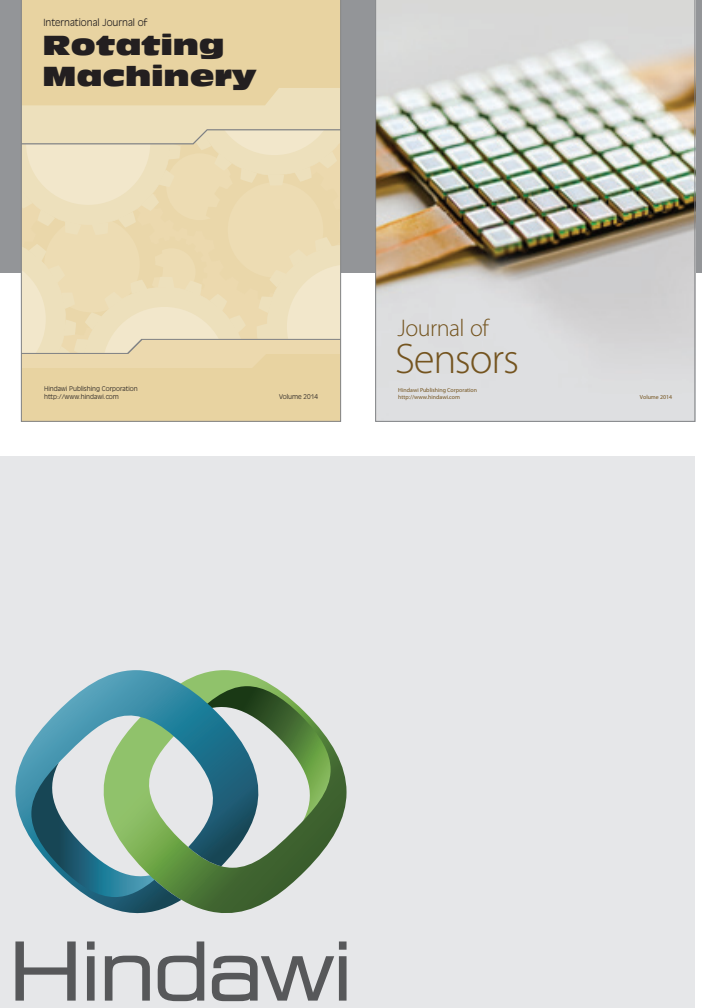

Submit your manuscripts at http://www.hindawi.com
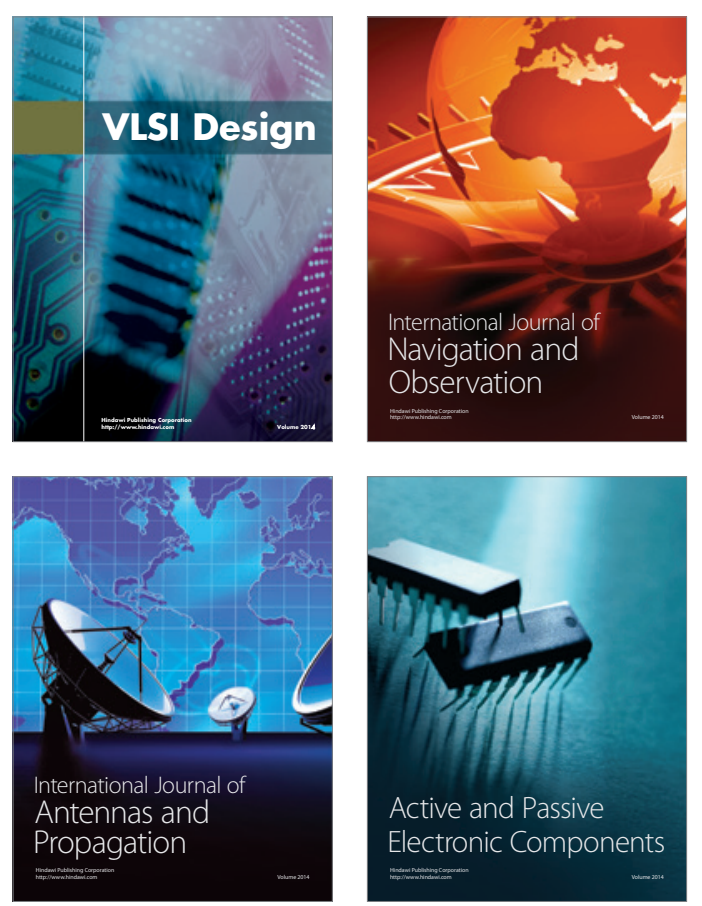
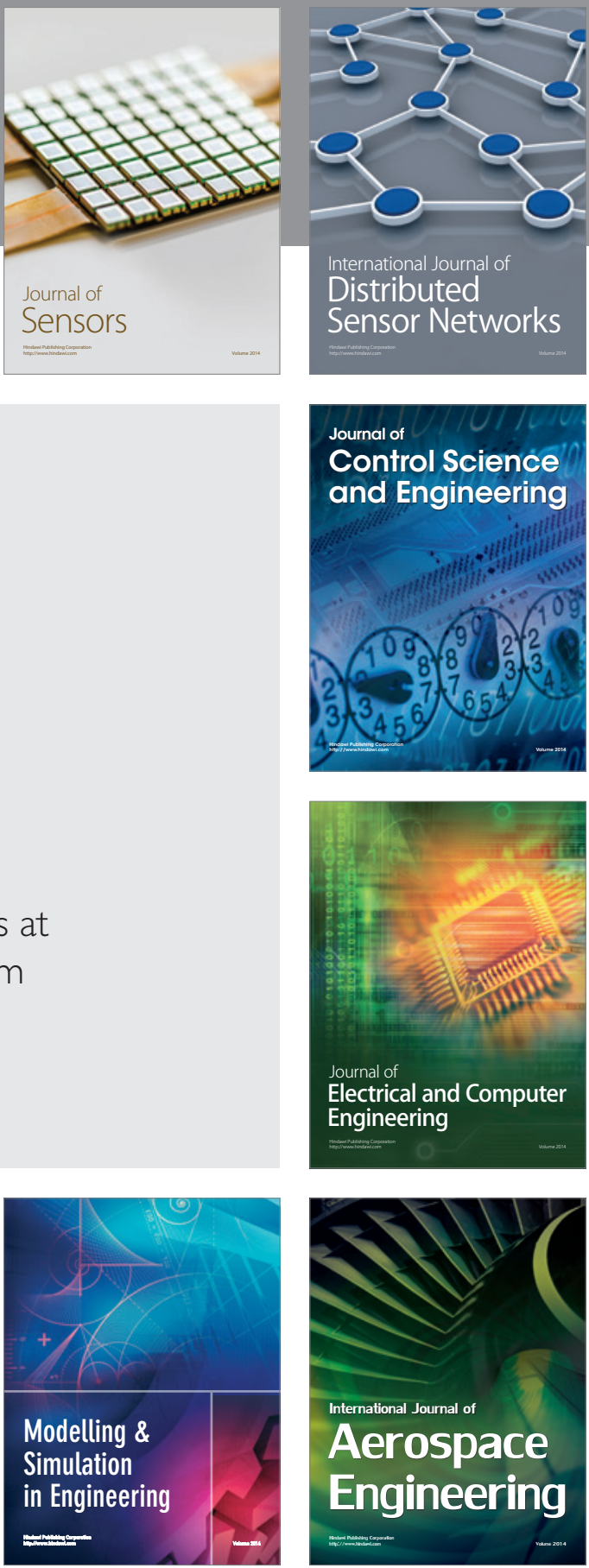

Journal of

Control Science

and Engineering
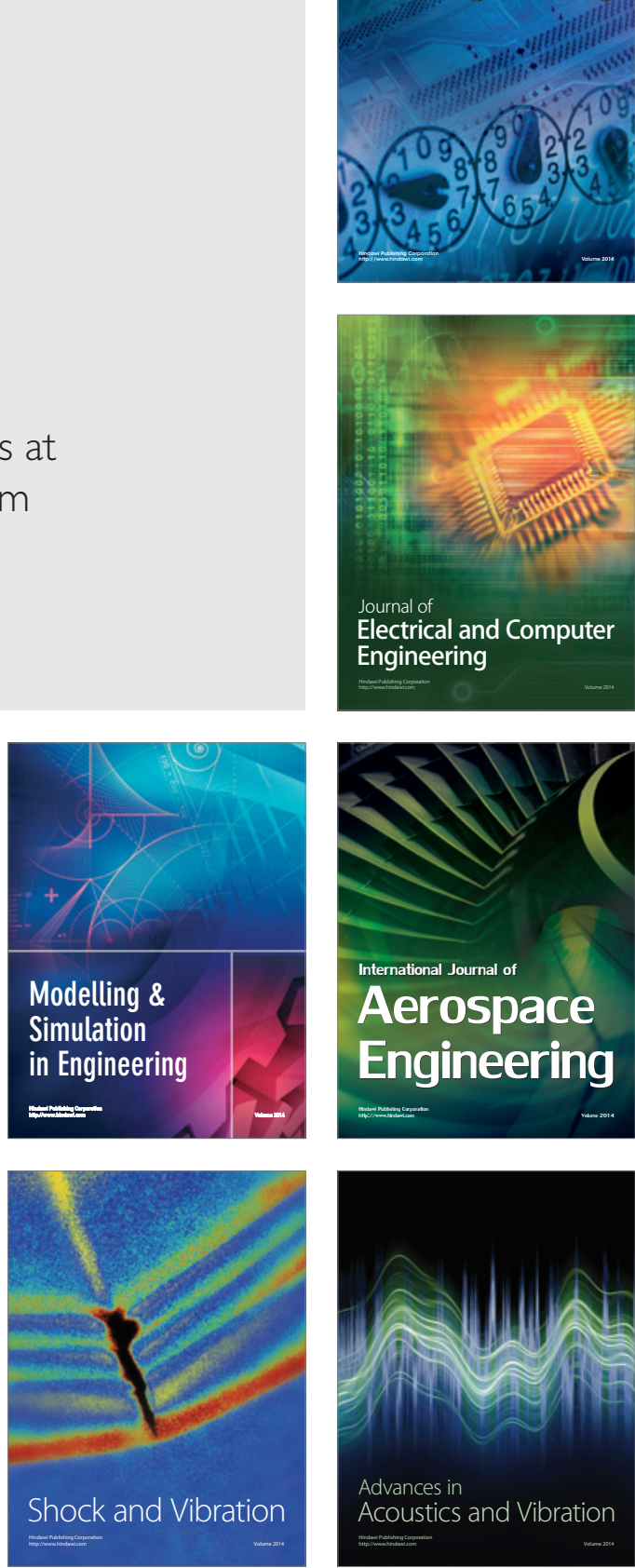